\title{
Mutant Alpha-Synuclein Causes Age-Dependent Neuropathology in Monkey Brain
}

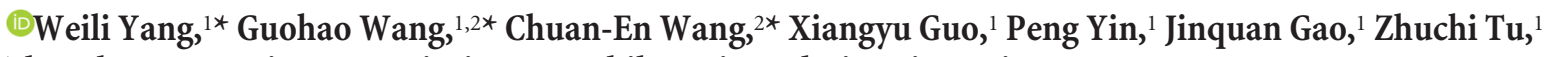 \\ Zhengbo Wang, ${ }^{3}$ Jing $\mathrm{Wu},{ }^{3}$ Xintian $\mathrm{Hu},{ }^{3}$ Shihua $\mathrm{Li}^{2}$ and Xiao-Jiang $\mathrm{Li}^{1,2}$ \\ ${ }_{1}^{1}$ State Key Laboratory of Molecular Developmental Biology, Institute of Genetics and Developmental Biology, Chinese Academy of Sciences, Beijing 100101, \\ China, ${ }^{2}$ Department of Human Genetics, Emory University School of Medicine, Atlanta, Georgia 30322, and ${ }^{3}$ Kunming Institute of Zoology, the Chinese \\ Academy of Sciences, Kunming, Yunnan 650223, China
}

Parkinson's disease (PD) is an age-dependent neurodegenerative disease that often occurs in those over age 60. Although rodents and small animals have been used widely to model PD and investigate its pathology, their short life span makes it difficult to assess the aging-related pathology that is likely to occur in PD patient brains. Here, we used brain tissues from rhesus monkeys at 2-3, 7-8, and $>15$ years of age to examine the expression of Parkin, PINK1, and $\alpha$-synuclein, which are known to cause PD via loss- or gain-of-function mechanisms. We found that $\alpha$-synuclein is increased in the older monkey brains, whereas Parkin and PINK1 are decreased or remain unchanged. Because of the gain of toxicity of $\alpha$-synuclein, we performed stereotaxic injection of lentiviral vectors expressing mutant $\alpha$-synuclein (A53T) into the substantia nigra of monkeys and found that aging also increases the accumulation of A53T in neurites and its associated neuropathology. A53T also causes more extensive reactive astrocytes and axonal degeneration in monkey brain than in mouse brain. Using monkey brain tissues, we found that A53T interacts with neurofascin, an adhesion molecule involved in axon subcellular targeting and neurite outgrowth. Aged monkey brain tissues show an increased interaction of neurofascin with A53T. Overexpression of A53T causes neuritic toxicity in cultured neuronal cells, which can be attenuated by transfected neurofascin. These findings from nonhuman primate brains reveal age-dependent pathological and molecular changes that could contribute to the age-dependent neuropathology in PD.

Key words: aging; degeneration; neurite; Parkinson's; primate

\section{Introduction}

Parkinson's disease (PD) is one of the most frequent neurodegenerative disorders, with classic motor symptoms characterized by bradykinesia, tremor, rigidity, and postural instability (Fearnley and Lees, 1991; Olanow and Tatton, 1999). The motor symptoms are related to the progressive loss of dopamine (DA) neurons in the substantia nigra pars compacta ( $\mathrm{SNpc}$ ), which leads to striatal DA depletion. Before the onset of motor symptoms, patients with PD also suffer from nonmotor symptoms, including olfactory impairments, gastrointestinal dysfunction, depression, sleep distur-

Received Feb. 25, 2015; revised March 31, 2015; accepted April 20, 2015.

Author contributions:W.Y., G.W., C.E.W., S.L., and X.-J.L. designed research; W.Y., G.W., C.-E.W., X.G., P.Y., J.G., Z.T., Z.W., and J.W. performed research; X.H. contributed unpublished reagents/analytic tools; W.Y., S.L., and X.-J.L. analyzed data; $X$.-J.L. wrote the paper.

This work was supported by the National Key Basic Research Program of China (Grant 2012CBA01304), the National Natural Science Foundation of China (Grant 91332206), the Strategic Priority Research Program of the Chinese Academy of Sciences (Grant XDB13000000), the National Institutes of Health (Grants AG19206 and NS041449 to X.J.L.), and the State Key Laboratory of Molecular Developmental Biology, China. We thank Weizhi Ji and Yunbo Liu for the use of monkey facilities; Lianhe Zhang, Qiang Sun, and Ruxiao Xing for technical assistance; Yi Hong for electron microscopic analysis; and Cheryl Strauss for critical reading of this manuscript.

The authors declare no competing financial interests.

*W.Y., G.W., and C.-E.W. contributed equally to this work.

Correspondence should be addressed to Xiao-Jiang Li, Department of Human Genetics, Emory University School of Medicine, 615 Michael Street, Room 347, Atlanta, Georgia 30322. E-mail: xli2@emory.edu.

DOI:10.1523/JNEUROSCI.0772-15.2015

Copyright $\odot 2015$ the authors $\quad 0270-6474 / 15 / 358345-14 \$ 15.00 / 0$ bances, and cognitive impairments (Becker, 2003; Ponsen et al., 2004; Stiasny-Kolster et al., 2005). Although PD is now considered a multisystem neurodegenerative disorder, most therapeutics are aimed at alleviating the motor symptoms that result from DA neuronal degeneration; however, the mechanisms underlying the selective degeneration of DA neurons remain unclear.

Although most cases of PD are sporadic, specific mutations in some genes cause familial forms of PD, which has led to a new approach in the study of PD. Identification of these mutant genes, which encode $\alpha$-synuclein ( $\alpha$-syn), Parkin, DJ-1, UCHL1, PINK1, and LRRK (Dawson et al., 2010; Brás et al., 2015), has allowed the generation of animal models of PD. Of these PD genes, overexpression of $\alpha$-syn is known to cause PD because duplication and triplication of wild-type $\alpha$-syn can also lead to PD in humans (Singleton et al., 2003; Chartier-Harlin et al., 2004). However, mutations in $\alpha$-syn may facilitate its accumulation and misfolding, resulting in Lewy bodies and neurodegeneration that are age dependent (Goedert, 2001; Neumann et al., 2002; Chung et al., 2013). Consistent with this idea, transgenic expression of mutant $\alpha$-syn in various animal models has proved to be toxic to neuronal cells and cause neurological symptoms (Lin et al., 2009; Dawson et al., 2010; Magen and Chesselet, 2011; Niu et al., 2015).

Although various transgenic mouse models of PD have been established and given us important insights into PD pathogene- 
sis, most transgenic mouse models do not show striking degeneration of DA neurons in the brain (Beal, 2010; Dawson et al., 2010). The failure of PD mouse models to replicate the cardinal neurodegeneration seen in PD patients could be due to species differences determined by genomic, molecular, and anatomic differences between rodents and humans. Therefore, nonhuman primates would allow us to explore whether PD pathology is in fact species dependent. In the current study, we found that overexpression of A53T causes more neuronal pathology in monkey brains than in mouse brains and that this neuropathological effect is also age dependent. In addition, we found that $\alpha$-syn interacts with neurofascin, an axonal protein that maintains the integrity of axons (Sherman et al., 2005; Kriebel et al., 2012). Furthermore, old monkey brains appear to enhance the interaction of mutant $\alpha$-syn with neurofascin, which may contribute to the age-dependent neuritic toxicity of mutant $\alpha$-syn. These findings from nonhuman primates suggest that species-dependent factors and neurofascin contribute to the neuropathology seen in PD.

\section{Materials and Methods}

Antibodies. Primary antibodies from commercial sources used in this study include: mouse anti-syn (Thermo Scientific, MS-1572-P1ABX); mouse or rabbit anti-NeuN, mouse anti-GAPDH, mouse anti-MAP2, and rabbit anti-tyrosine-hydroxylase (Millipore); rabbit anti-GFAP (DAKO); rabbit anti-ECFP (Clontech Laboratories); and antibodies to Parkin, PINK1 (Santa Cruz Biotechnology, sc-32282, sc-33796), and $\alpha$-syn (Proteintech,10842-1-AP). All secondary antibodies were purchased from Jackson ImmunoResearch and Invitrogen.

Lentiviral preparation and stereotaxic injection. To generate lentivirus vector expressing A53T, a PCR product of A53T (cDNA plasmid, provided by Dr. Ken Nakamura at University of California-San Francisco, was used as a template) was in-frame fused with the F2A-ECFP fragment and inserted into pFUGW lentiviral vector. The self-cleavage of F2A separates A53T protein from ECFP in cells. Lentiviral A53T and GFP viruses at $10^{9}$ viruses $/ \mathrm{ml}$ were produced by The Viral Vector Core at Emory University.

All animal procedures were approved in advance by the Institutional Animal Care and Use Committee at Emory University or the Kunming Institute of Zoology, Chinese Academy of Sciences. For virus injection into the mouse brain, mice were anesthetized with a solution of Avertin $(12.5 \mathrm{mg} / \mathrm{ml}$; Sigma, T48402) at $250 \mathrm{mg} / \mathrm{kg}$ body weight intraperitoneally. The mice were then stabilized on a stereotaxic instrument (David Kopf Instruments). Stereotactic coordinates for the substantia nigra were obtained from the Franklin and Paxinos Mouse Brain Atlas (AP: $-3 \mathrm{~mm}$, ML: $-1.5 \mathrm{~mm}$ (both from bregma), DV: $4.4 \mathrm{~mm}$ below skull). One or two microliters of viruses were bilaterally injected into each wild-type C57/B6 mouse brain.

Viral injection of monkey brains was performed using the facilities at Kunming Institute of Zoology, the Chinese Academy of Sciences, and Kunming Biomed International, Kunming, China. For virus injection into the monkey substantia nigra, each monkey was anesthetized by intraperitoneal injection of $0.3-0.5 \mathrm{ml}$ of atropine, followed by $10-12 \mathrm{mg}$ of ketamine and 15-20 mg of pelltobarbitalum natricum per kg body weight. The monkeys were then stabilized on a stereotaxic instrument (David Kopf Instruments). The precise position of the substantia nigra for stereotaxic injection was located by MRI before injection. Five to eight microliters of viruses were injected into one side of the monkey substantia nigra. Brain tissues from rhesus monkeys at different ages were obtained from aging-related studies of monkeys at the Institute of Laboratory Animal Sciences, Chinese Academy of Medical Sciences, and Peking Union Medical College, Beijing, China.

Western blotting, immunohistochemical studies, and electron microscopy. For Western blots, the front cortex tissues from male rhesus monkeys of different ages, which were freshly isolated and kept at $-80^{\circ} \mathrm{C}$ to study the age-related effects on primate brain proteins, were homogenized in RIPA buffer (50 mм Tris, pH 8.0, 150 mm NaCl, 1 mм EDTA pH
8.0, 1 mm EGTA, pH 8.0, 0.1\% SDS, 0.5\% DOC, and 1\% Triton X-100) with $1 \times$ protease inhibitor (Sigma, P8340). The tissue lysates were diluted in $1 \times$ SDS sample buffer $(62.6 \mathrm{~mm}$ Tris- $\mathrm{HCl}$, pH 6.8, $2 \%$ SDS, $10 \%$ glycerol, and $0.01 \%$ bromophenol blue) and sonicated for $10 \mathrm{~s}$ after incubation at $100^{\circ} \mathrm{C}$ for $5 \mathrm{~min}$. The total lysates were resolved in a $4-20 \%$ Tris-glycine (Invitrogen) and blotted to a nitrocellulose membrane. Western blots were developed using the ECL Prime kit (GE Health Care). For quantification of Western blot results, each monkey brain tissue was analyzed at least three times. Brain tissues from multiple monkeys (four to seven monkeys per group) were analyzed via Western blotting analysis. Multiple samples in the same blots were probed with antibodies to interesting proteins and GAPDH, which served as a loading control. The signals of the immunoreactive bands were quantified with densitometry analysis using the software Image-ProPlus (Vierck et al., 2000). The ratios of immunolabeled proteins to GAPDH were then used to compare the relative levels of the detected proteins in the same brain tissues from monkeys at different ages.

Methods for immunohistochemistry and electron microscopy were described previously (Wang et al., 2008). For immunohistochemistry, monkey brain tissues were prefixed by $4 \%$ paraformaldehyde in $0.1 \mathrm{M}$ phosphate buffer (PB), pH 7.2. Brain blocks were removed, cryoprotected in $30 \%$ sucrose at $4^{\circ} \mathrm{C}$, and sectioned at $40 \mathrm{~mm}$ using a cryostat (Leica, CM1850). Light micrographs were taken using a Zeiss microscope (Axiovert 200 MOT) equipped with a digital camera (Orca-100; Hamamatsu). For electron microscopy, the monkey brain was perfused with $4 \%$ paraformaldehyde in $0.1 \mathrm{M} \mathrm{PB}, \mathrm{pH} 7.2$, with $2.5 \%$ glutaraldehyde and postfixed in $4 \%$ paraformaldehyde $/ 0.1 \mathrm{~m} \mathrm{~PB}$ overnight. Brains were sectioned into $50 \mu \mathrm{Cm}$ using a vibratome (Leica, VT1000s) and the sections were processed for electron microscopic examination. In brief, all sections were osmicated in $1 \% \mathrm{OsO}_{4}$ in $0.1 \mathrm{M} \mathrm{PB}$ and embedded in Eponate12 (Ted Pella). The dried brain sections were cut into ultrathin sections $(60 \mathrm{~nm})$ with a Leica Ultracut $S$ ultramicrotome under a Hitachi H-7500 transmission electron microscope equipped with a Gatan BioScan CCD camera at Emory University.

Histological quantification. To quantify neurons expressing transgenic A53T in transgenic monkey fetus brain (Niu et al., 2015), we used 5-8 images obtained with a $20 \times$ numerical aperture (NA) 0.8 objective per section and 5 sections per group ( 3 or more animals per group). Neurons that were clearly labeled by anti- $\alpha$-syn were counted to obtain the mean values \pm SEM per image. Wild-type monkey fetus brain served as a control. Images were collected from at least five different randomly selected areas per brain section.

In lentiviral A53T-injected monkey and mouse brains, electron microscopy images were used to identify reactive astrocytes. Quantification of reactive astrocytes was obtained by examining 10,000 $\times$ magnification images and the mean values \pm SEM were obtained from five to six images per section and six sections in each group. To count neurons containing Lewy neurites in the lentiviral A53T-injected monkey brains, photo images of the lentiviral-injected brain region were examined using a $40 \times$ objective, NA 0.95. Lewy neurites are defined as neuronal processes that comprise abnormal $\alpha$-synuclein aggregates or granular material and often show clear interruptions and swellings in the segment (Spillantini et al., 1998). The mean values \pm SEM of neurons containing Lewy neurites per image $(40 \times$ objective, NA 0.95$)$ were obtained from $4-6$ images per section and 5-7 sections per group. Dopaminergic neurons, which are labeled by anti-tyrosine-hydroxylase (TH), were also counted in the substantia nigra. Images of the substantia nigra sections were captured using a $10 \times$ NA 0.3 objective. TH-immunoreactive cells in lentiviral GFP- or A53T-injected sections were counted by examining $\sim 10$ fields per section in a series of stained sections $(n=5)$. To measure GFAP immunostaining intensity, ImageJ software was used. Colored images obtained with a $40 \times$ objective, NA 0.95 , were first converted to 8-bit black-andwhite images. The "Threshold" function was used to adjust the background to highlight GFAP-specific staining. The same threshold was applied to all images analyzed. Finally, the "Measure" function was used to quantify GFAP staining intensity in each image. Each group had five to seven images per slide and five slides per group were examined.

Protein interaction studies. GST-A53T was produced in bacteria (BL21 DE3) and purified with glutathione beads. The tissue lysates from the 
substantia nigra of a 22-year-old rhesus monkey were incubated with glutathione beads containing GST or GST-A53T. The pulldown proteins were subjected to SDS-PAGE. The bands of interest in the gel were isolated for identification of their natures by mass spectrometry on an LTQOrbitrap ion trap mass spectrometer (Thermo Finnigan). For immunoprecipitation, the brain cortex and substantia nigra of 8-yearold monkeys were homogenized in NP-40 buffer ( $50 \mathrm{~mm} \mathrm{NaCl}, 50 \mathrm{~mm}$ Tris- $\mathrm{HCl}$ pH 8.0, 0.1\% Triton X-100, 0.5\% NP-40). Protein concentration was determined with a BCA protein assay kit (Thermo Scientific, 23227) and $500 \mu \mathrm{g}$ of proteins were incubated with primary antibody overnight. Protein A-agarose $(20 \mu \mathrm{l})$ was then added to the mixture and the sample mixtures were rotated for an additional $1 \mathrm{~h}$ at $4^{\circ} \mathrm{C}$. The precipitated antibody-protein complexes were used for Western blotting.

Purified GST-A53T was also incubated with the recombinant HAtagged neurofascin, which was purified and purchased from Neuromics at different doses $(0-2.5 \mu \mathrm{g})$. After incubation, GST-A53T was isolated by binding to glutathione beads and precipitated via centrifugation. The bound proteins were analyzed by Western blotting of the precipitated proteins.

To study the interactions of GST-A53T with endogenous neurofascin in the brain tissues of monkeys at different ages, monkey front cortex tissue lysates were incubated in buffer $(50 \mathrm{~mm} \mathrm{NaCl}, 50 \mathrm{~mm}$ Tris- $\mathrm{HCl}, \mathrm{pH}$ 8.0, $0.1 \%$ Triton X-100, $1 \%$ NP-40) with the same amounts $(15 \mu \mathrm{g})$ of GST or GST-A53T for $8 \mathrm{~h}$ at $4^{\circ} \mathrm{C}$. After incubation, glutathione beads were added to precipitate GST and GST-A53T. The beads were washed 3 times with PBS ( 1 min each time). The precipitated beads were then subjected to Western blotting with antibodies to neurofascin and $\alpha$-synuclein. The ratios of bound neurofascin to the input and the precipitated GST-A53T were obtained by densitometry and used for comparison of the relative amounts of neurofascin pulled down by GSTA53T. Brain tissues from three monkeys per age group and multiple ( $>$ three) replicated Western blots for the same sample were analyzed.

Cell cultures. PC12 cells were cultured in DMEM supplemented with $10 \%$ horse serum, $5 \%$ fetal bovine serum, $100 \mathrm{U} / \mathrm{ml}$ penicillin, $100 \mu \mathrm{g} / \mathrm{ml}$ streptomycin, and $0.25 \mu \mathrm{g} / \mathrm{ml}$ amphotencin B. To evaluate neurite outgrowth, PC12 cells were treated with NGF $(100 \mathrm{ng} / \mathrm{ml})$. Neurofascin (Addgene) and A53T were individually expressed or cotransfected into PC12 cells. PC12 cells were treated with NGF (100 ng/ml) for $48 \mathrm{~h}$. For transient transfections, cells were plated at $85 \%$ confluence and transfected with $4 \mu \mathrm{g}$ (for 6-well plates) of plasmid DNA using Lipofectamine 2000 (Invitrogen) for $24-48 \mathrm{~h}$. Transfected cells were imaged randomly to quantify cells with normally elongated neurites that were longer than two cell bodies and at least 60 transfected cells per group were used for statistical analysis.

Striatal and cortical neurons were isolated from embryonic day 18 mouse brains. Dissected tissues were treated with $0.0625 \mathrm{mg} / \mathrm{ml}$ trypsin in $1 \times$ HBSS buffer without calcium or magnesium for $10 \mathrm{~min}$ at $37^{\circ} \mathrm{C}$, followed by triturating with a $1 \mathrm{ml}$ pipette tip 20 times. Cells were then washed once with the tissue culture medium and centrifuged at $500 \times g$ for $3 \mathrm{~min}$. Cells were plated on glass coverslips that had been precoated with $0.1 \mathrm{mg} / \mathrm{ml}$ poly-D-lysine and $1 \mu \mathrm{g} / \mathrm{ml} \mathrm{laminin}$, and grown in neurobasal/B27 medium at $10^{5} / \mathrm{ml}$. The cultured cells at $4-7 \mathrm{~d}$ in vitro (DIV) were infected with lentiviral A53T vector at $10^{7-} 10^{8}$ viruses $/ \mathrm{ml}$. After $48-72 \mathrm{~h}$, the infected cells were examined for the expression of A53T.

Statistical analysis. Differences between two groups were evaluated by Student's $t$ test. One-way ANOVA with the Bonferroni post hoc correction was performed to determine pairwise comparisons among multiple datasets and the results were expressed as the mean \pm SEM. $p<0.05$ was considered significant.

\section{Results}

Age-dependent expression of PD proteins in monkey brains

Although PD is an age-dependent disorder, how aging influences the expression of the disease proteins in primate brains has not been investigated. We were able to obtain the front cortex tissues of a number of monkeys of the same sex (male) at different ages $(2-3,7-8$, and $15-18$ years). Given the average life span $(25$ years) of rhesus monkeys, the ages $(2-3,7-8$, and $>15$ years) of rhesus monkeys are equivalent to human ages at $7-12,25-28$, and $>53$ years. These monkey brain tissues were isolated freshly from euthanized animals that were used for an aging-related study and allowed us to use Western blotting analysis to examine the expression of $\alpha$-syn, Parkin, and PINK1 in the brains of rhesus monkeys at different ages. Each age group consisted of brain cortex samples from three to six male rhesus monkeys. The brain homogenates of monkeys were subjected to Western blotting with antibodies to $\alpha$-syn, Parkin, and PINK1. The same blots were also probed with an antibody to GAPDH, which served as an internal control for assessing the amount of proteins loaded in the gel. Western blotting results show that there are increased levels of $\alpha$-syn and Parkin from young ( $2-3$ years) to adult (7-8 years) monkey brains. However, in the old monkeys ( $>15$ years), $\alpha$-syn continues to increase whereas Parkin decreases (Fig. 1A). Levels of PINK1 do not seem to be significantly altered at different ages (Fig. 1B). The age-dependent differences in the levels of $\alpha$-syn, Parkin, and PINK1 were verified by quantifying their ratios to GAPDH on the same blots (Fig. 1C).

\section{Age-dependent increase in Lewy neurites and neuropathology in monkey brains}

Because overexpression of either wild-type or mutant $\alpha$-syn can cause PD (Giasson et al., 2002; Lo Bianco et al., 2002; Singleton et al., 2003; Chartier-Harlin et al., 2004), we focused on $\alpha$-syn accumulation in aged monkey brains. The age-dependent increase in $\alpha$-syn in the monkey brains could be due to either reduced clearance or increased expression of $\alpha$-syn with age. The substantia nigra is a defined small region in the brain. Although we could not obtain enough fresh tissues from the substantia nigra of monkeys for Western blotting analysis, we wanted to use stereotaxic injection of lentiviral vector to express mutant $\alpha$-syn (A53T) in this monkey brain region to compare its toxicity at different ages. Therefore, we expressed the same amount of exogenous mutant $\alpha$-syn (A53T) in monkey brains via stereotaxic injection of viral vectors to explore whether aging leads to greater accumulation of mutant $\alpha$-syn. A53T is linked to ECFP via F2A, which can be self-cleaved in cells to separate A53T from ECFP and is ubiquitously expressed under the human ubiquitin promoter (Fig. 2A). By infecting cultured primary neuronal cells from the cortex and striatum of mouse brains, we verified that the purified virus effectively infected primary neuronal cells in vitro (Fig. 2B).

After confirming the expression of A53T in cultured neuronal cells by the lentiviral A53T vector, we performed stereotaxic injection of this viral vector into the substantia nigra of rhesus monkeys and used immunocytochemical assays to evaluate the expression of A53T (Fig. 3A). In our initial study, the control monkey was injected with PBS. We could identify the injected pathway along which A53T labeling was clearly seen in the lentiviral A53T- but not the PBS-injected monkey brain. Because the anti- $\alpha$-syn that we used reacts weakly with the endogenous monkey $\alpha$-syn, there is clearly immunolabeling of viral A53T in the cells in the viral A53T-injected site compared with the PBSinjected region (Fig. 3B). Furthermore, A53T formed small aggregates in long neuronal processes that showed fragments reminiscent of Lewy neurites in PD patient brains (Fig. 3C).

Next, we stereotaxically injected monkeys using lentiviral A53T vector and the control lentiviral-GFP vector. Rhesus monkeys at different ages $(2,8$, and 22 years) were given the same doses of lentiviral vectors in the substantia nigra and allowed to express A53T or GFP for the same period of time (8 weeks). The animals were then euthanized to isolate their brains for analysis of A53T expression. Compared with the control monkeys that were 
A
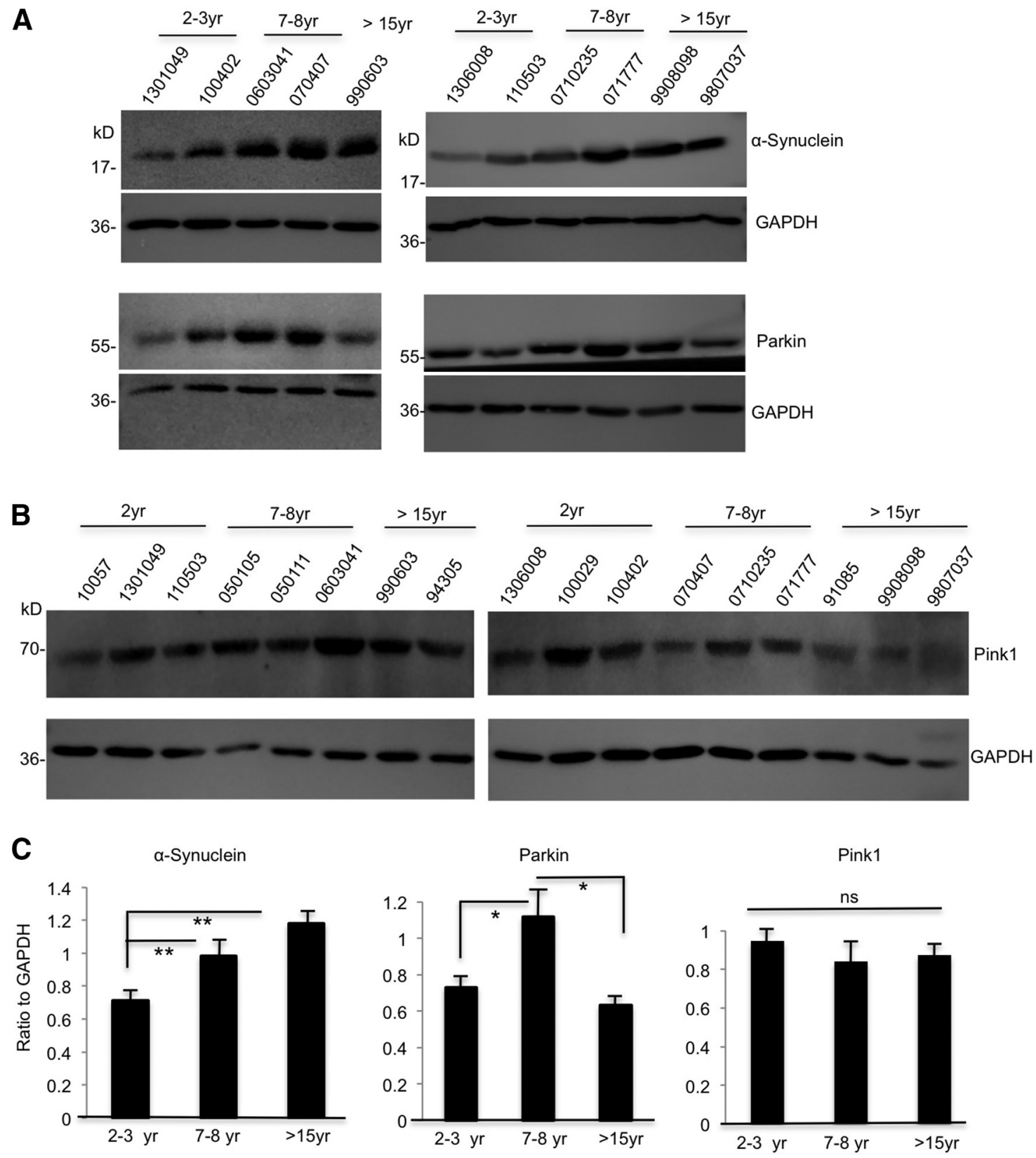

Figure 1. Age-dependent expression of Parkin, PINK1, and $\alpha$-syn in monkey brains. $A, B$, Western blot analysis of brain cortical tissues from rhesus monkeys at the ages of $2,7-8$, and $>15$ years. The front cortical tissues from individual monkeys were analyzed by Western blotting with antibodies to $\alpha$-syn, Parkin $(\boldsymbol{A})$, and PINK1 ( $\boldsymbol{B})$. Anti-GAPDH was used to probe the same blots to reflect the loading amounts. $C$, Ratios of $\alpha$-syn, Parkin, and PINK1 to GAPDH were obtained by densitometry and presented as mean \pm SE. Three or more monkey brains for each age group were examined. ${ }^{*} p<0.05,{ }^{* *} p<0.01$.

injected with lentiviral GFP, we also verified the specific expression of A53T in the injected area (Fig. 4A). As expected, A53T forms Lewy neurites in the injected brains of monkeys at different ages. Importantly, the density of Lewy neurites is more abundant in older monkey brains (Fig. 4A). Because A53T overexpression can mediate neuropathology in transgenic animal models (Eslamboli et al., 2007; Lin et al., 2009; Dawson et al., 2010; Magen and Chesselet, 2011; Niu et al., 2015), we examined reactive astrocytes, which reflect early neuronal damage, to assess neuropathology in the injected brain regions. Using antibody to GFAP, an astrocyte-specific protein, we also found more reactive astrocytes in the older monkey brain region after injection with lentiviral A53T (Fig. 4C). We then quantified the density of Lewy neurites and reactive astrocytes in the injected brain regions in monkeys of different ages via immunohistochemical analysis. The quantification revealed that Lewy neurites and reactive astrocytes were indeed increased in aged monkey brains, indicating that aging promotes A53T-mediated neuronal toxicity in the monkey brain (Fig. 4D).

\section{A53T-mediated axonal degeneration in monkey brain}

We next performed electron microscopy (EM) to examine the neuropathology caused by viral A53T injection and found that reactive astrocytes and axonal degeneration were specifically present in the viral A53T-injected, but not viral GFP-injected, substantia nigra (Fig. 5A). High-magnification EM clearly shows the increase in reactive astrocytes and degenerated axons, characterized by swollen and enlarged axons in which dark and degenerated organelles are evident (Fig. 5B). TH staining is an 
A

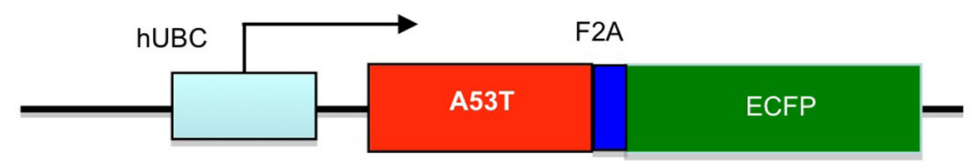

B
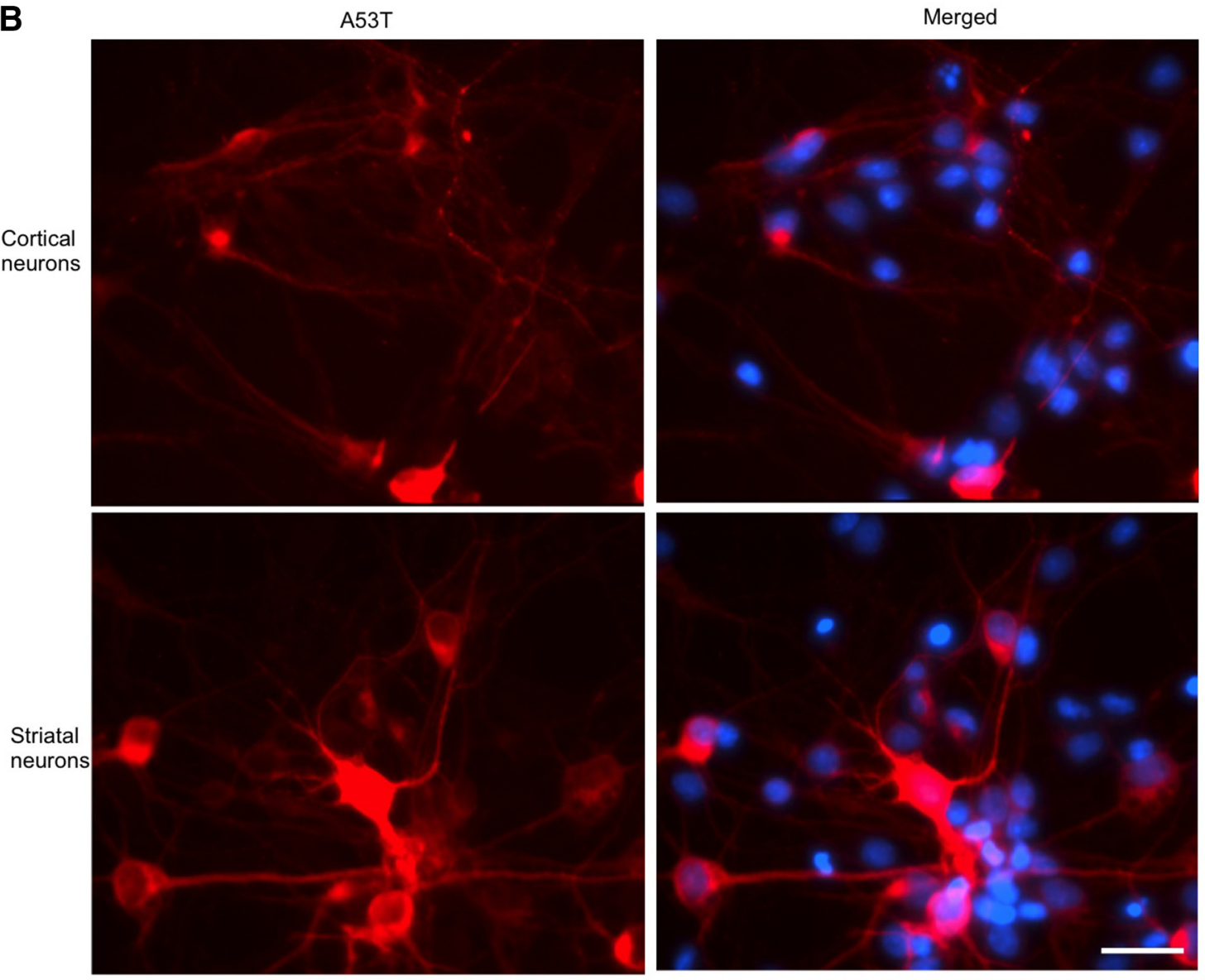

Figure 2. Expression of A53T via lentiviral vector. $\boldsymbol{A}$, Structure of lentiviral vector expressing A53T under the control of the human ubiquitin promoter. $\boldsymbol{B}$, Cultured mouse brain cortical and striatal neurons transduced by lentiviral A53T showing positive staining by anti- $\alpha$-syn (red). The nuclei of cells were stained by Hoechst dye (blue). Scale bar, $20 \mu \mathrm{m}$.

established way to assess the degeneration of dopaminergic neurons. This staining also revealed a reduction in the number of TH-positive dopaminergic neurons in the substantia nigra of lentiviral A53T-injected monkeys (Fig. 5C). All of these findings provide evidence for A53T-mediated neuropathology and toxicity in primate brain tissues.

\section{Mutant $\alpha$-syn causes more degeneration in monkey brains than mouse brains}

We next compared the toxicity of A53T in mouse and monkey brain tissues. Because aging processes in 10-month-old mice correspond approximately to 8-year-old monkeys (Eslamboli et al., 2007), we compared the injected brain regions from these two groups. Similar to the previous findings (Lo Bianco et al., 2002), injection of the viral vector expressing A53T into the substantia nigra of mice also leads to the accumulation of A53T and Lewy neurites (Fig. 6A). The density of neuritic A53T in the injected mouse brain region was equivalent to or more than in the injected brains of 8-year-old monkeys, but was certainly less than in the 22-year-old monkey (Fig. 6B). Therefore, we compared ultrastructural images of the injected substantia nigra in 10-monthold mice and 8-year-old monkeys. We counted the number of reactive astrocytes because this quantification offers more direct evidence for early neuropathology in the brain. Electron microscopic examination revealed an increased amount of reactive astrocytes in the injected substantia nigra in the monkey brain compared with the mouse brain (Fig. 6C). Quantification of EM images for the number of reactive astrocytes in the injected mouse and monkey brains also confirmed that A53T caused more reactive astrocytes in the monkey brains (Fig. 6D).

\section{Mutant $\alpha$-syn interacts with neurofascin in monkey brains}

To further explore the mechanism behind this neuronal process degeneration, we used a GST-pulldown assay to identify neuronal proteins that could abnormally bind GST-A53T in rhesus monkey brain. GST and GST-A53T were generated and purified for incubation with the substantia nigra lysates from monkey brains. Silver staining of the SDS gel revealed some extra bands that were specifically present in the GST-A53T pulldown (Fig. $7 A$ ). Mass spectrometry analysis of these pulldowns revealed neurofascin, an adhesion protein that can interact with different partners both extracellularly and intracellularly to maintain axon integrity and promote neurite outgrowth (Zhang et al., 1998; Sherman et al., 2005; Kriebel et al., 2012). Neurofascin consists of 


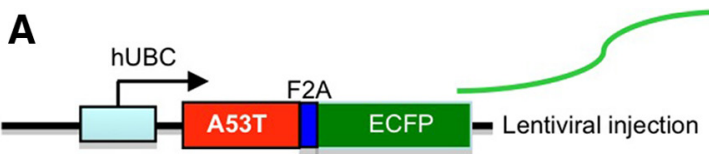

B
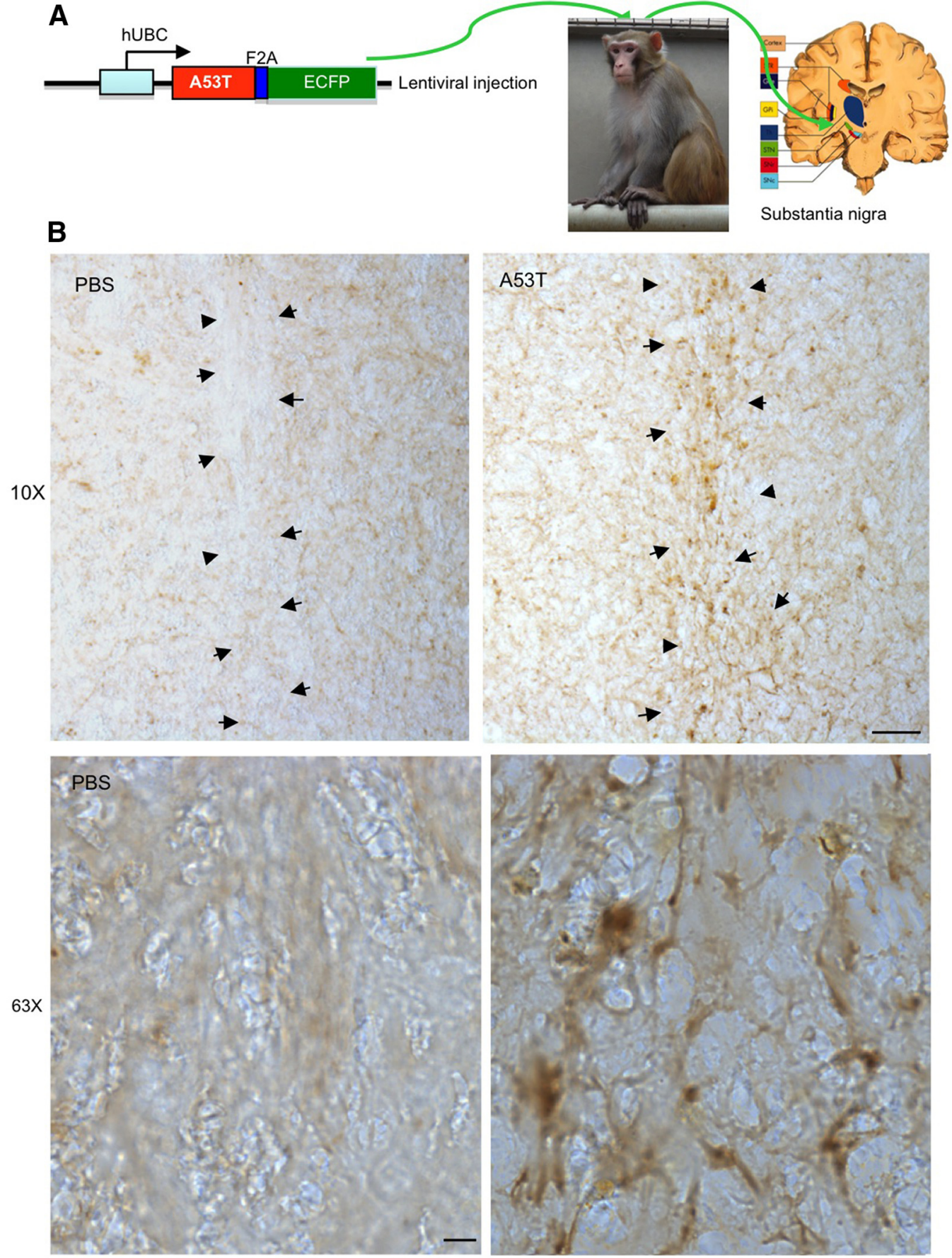

C

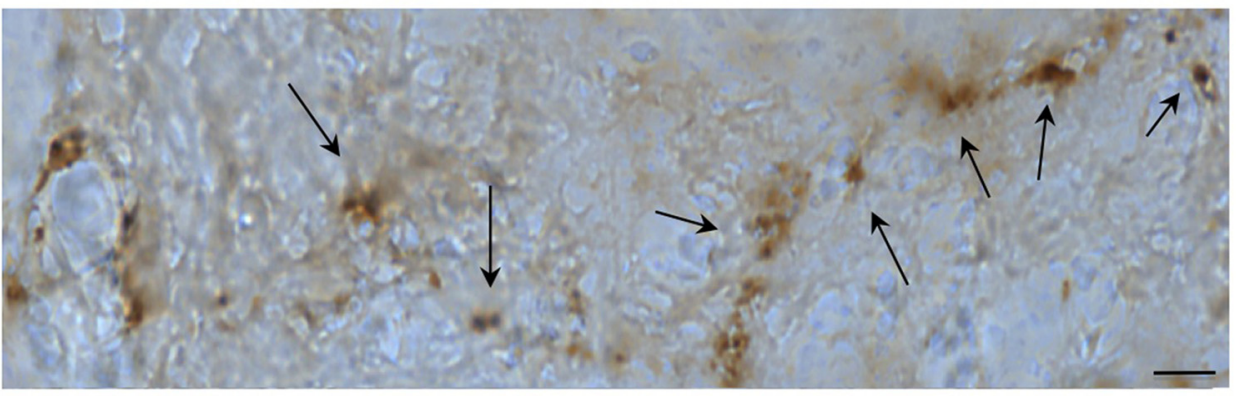

Figure 3. Expression of lentiviral A53T in the monkey brain. $\boldsymbol{A}$, Stereotaxic injection of lentiviral A53T into the substantia nigra of rhesus monkeys. $\boldsymbol{B}$, Immunostaining of the control injection (PBS) and lentiviral A53T-injected regions in the left and right substantia nigra, respectively, of the same monkey at 8 years of age. The brain sections were stained with anti- $\alpha$-syn. Scale bars: Top, $50 \mu \mathrm{m}$ (top); bottom, $5 \mu \mathrm{m}$. C, A53T forms puncta (arrows) in long process of neurons, which resemble Lewy neurites in PD patient brains. Scale bar, $5 \mu \mathrm{m}$. 

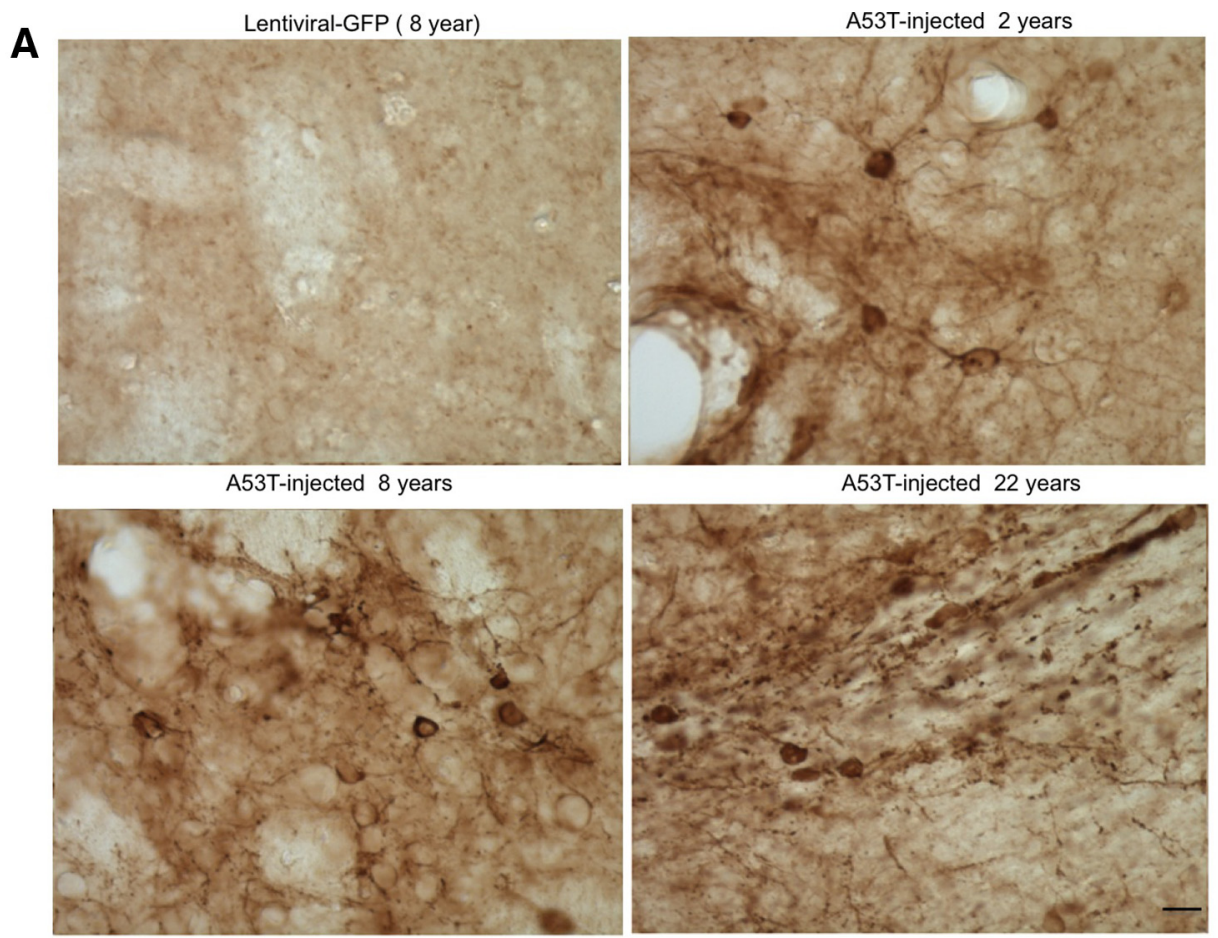

B
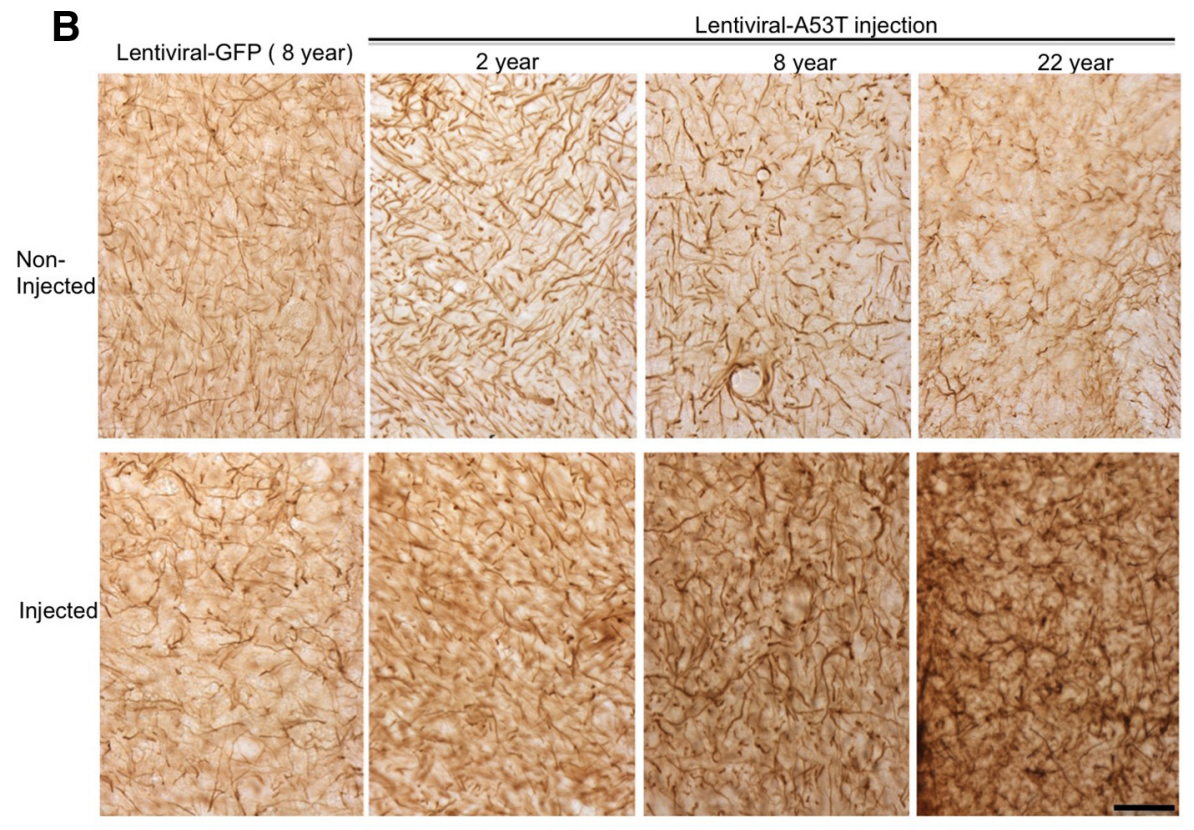

C
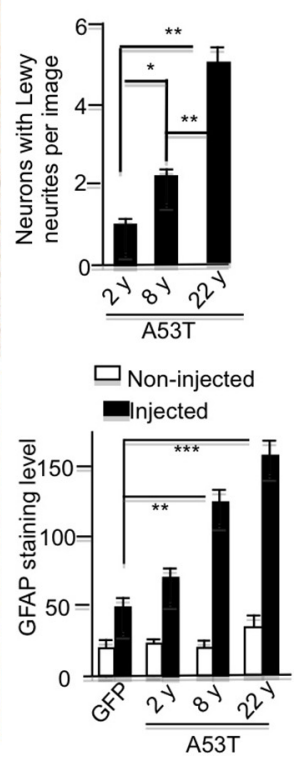

Figure 4. Aging promotes the accumulation and neuronal toxicity of A53T in rhesus monkeys. A, Anti- $\alpha$-syn staining of the A53T-injected substantia nigra of monkeys at 2, 8, and 22 years of age. Control is the lentiviral-GFP-injected substantia nigra of monkey brain at 8 years of age. $\boldsymbol{B}$, Increased density of reactive astrocytes with age in lentiviral A53T-injected monkey brain regions. Top and bottom images are from the noninjected and injected substantia nigra, respectively. Brain sections were stained by an antibody to GFAP. Scale bars, $10 \mu \mathrm{m}$. C, Quantitation of the number of neurons with Lewy neurites per image $(400 \times)$ (top) and GFAP staining levels (bottom) of the monkey brain tissues injected with lentiviral A53T. The data are mean \pm SEM from randomly selected images (5-10) per section ( $n=5-8$ sections). The control substantia nigra regions without lentiviral A53T (noninjected) in the same monkey brain were used as a control. GFAP staining levels were quantified via ImageJ software as the relative intensity over the background. ${ }^{* *} p<0.01,{ }^{* * *} p<0.001$ compared with the lentiviral GFP-injected region in 8 -year-old monkey. The following $p$-values were obtained for lentiviral A53T-injected monkeys: 2 years vs 8 years, $p=0.080 ; 2$ years vs 22 years, $p=0.0068$; and 8 years vs 22 years, $p=0.1759$.

different isoforms of 186, 180, 166, and $155 \mathrm{kDa}$ generated by alternative splicing (Hassel et al., 1997). Because the limited monkey substantia nigra tissues had been used up for mass spectrometry, we used monkey cortical tissues to perform immunoprecipitation to confirm the in vivo interaction of $\alpha$-syn and neurofascin because both proteins are expressed in the cortex and other brain regions. Immunoprecipitation of the cortex tissues of rhesus monkeys with anti- $\alpha$-syn confirmed the in vivo interaction of neurofascin with $\alpha$-syn (Fig. 7B). Using GST-A53T to incubate with purified recombinant neurofascin, we also obtained evidence for their direct interaction (Fig. 7C). Furthermore, using immunoprecipitation of the tissue lysates from monkey brain substantia nigra that had been injected with lentiviral A53T for immunoprecipitation, we verified that overex- 

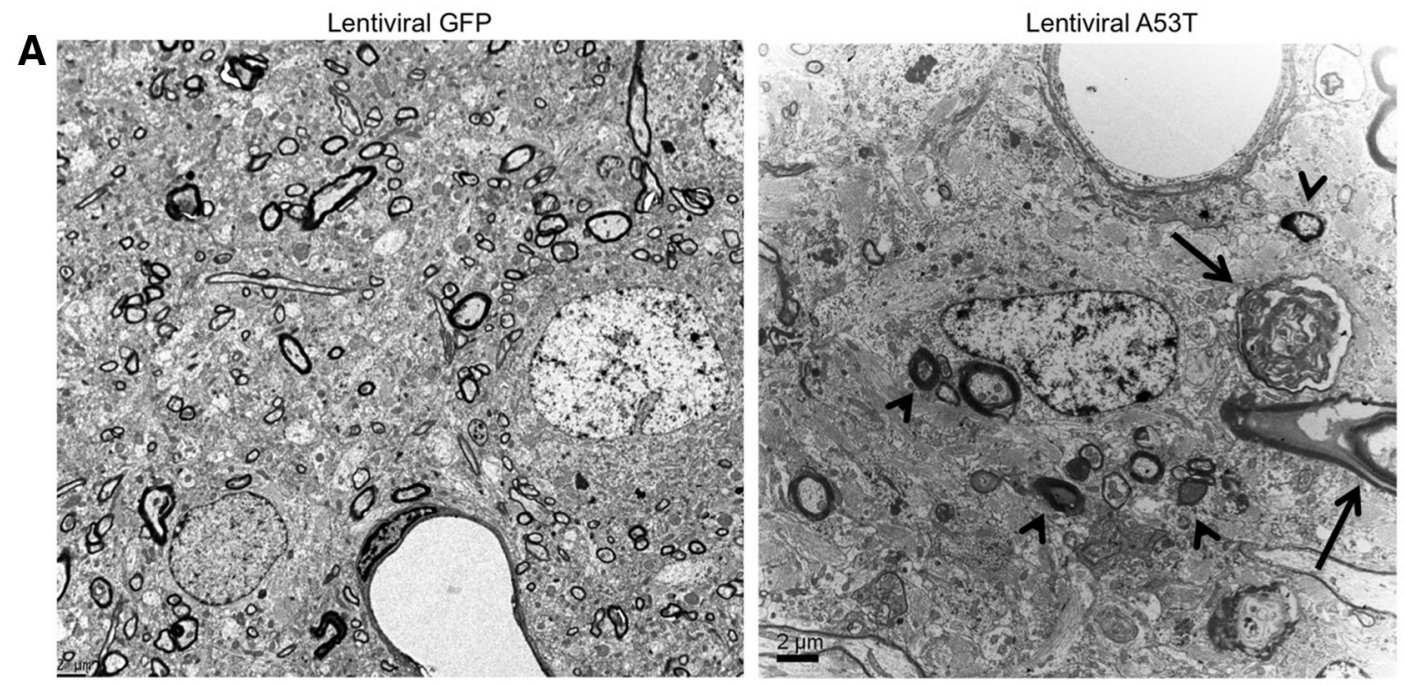

B
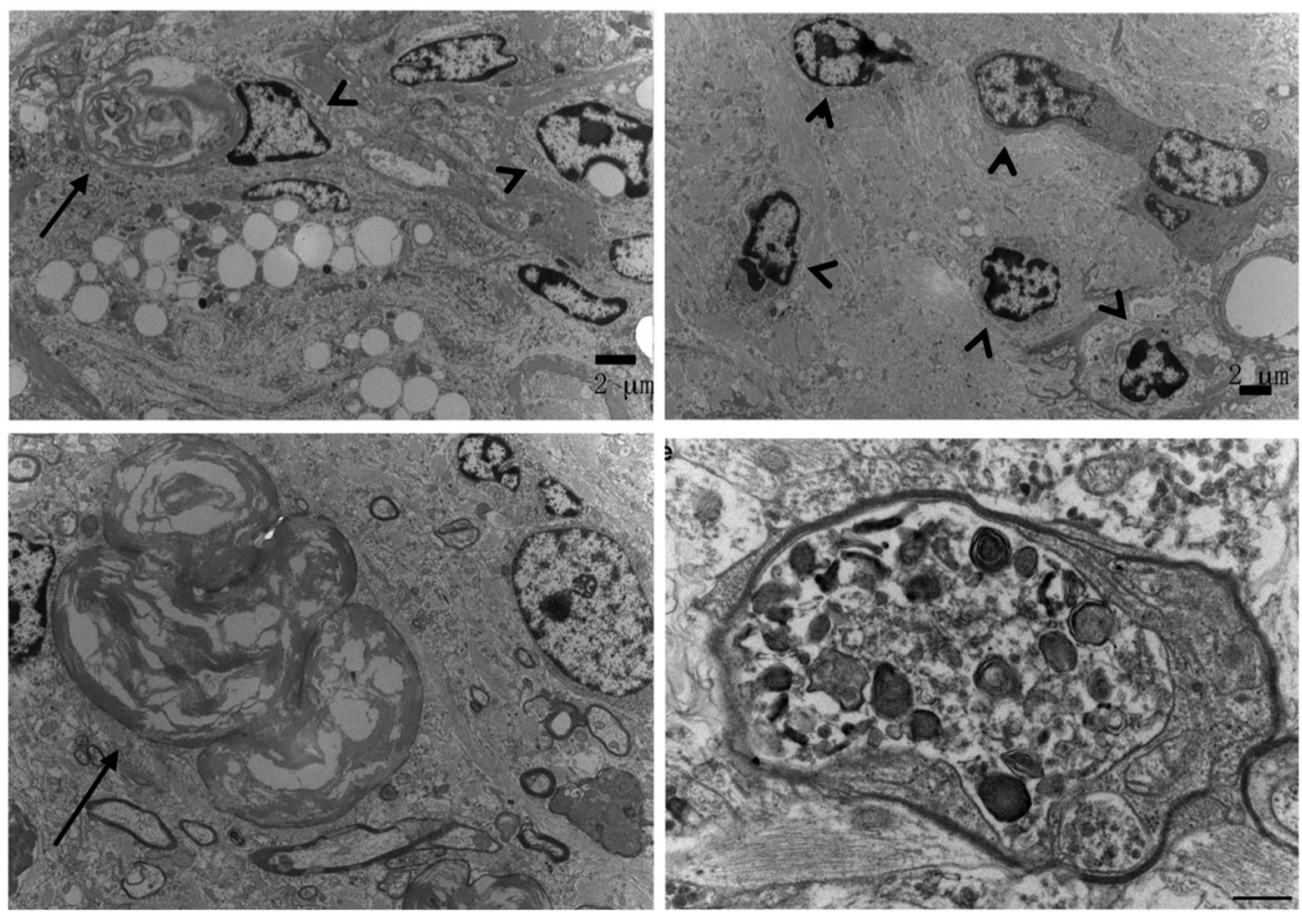

C
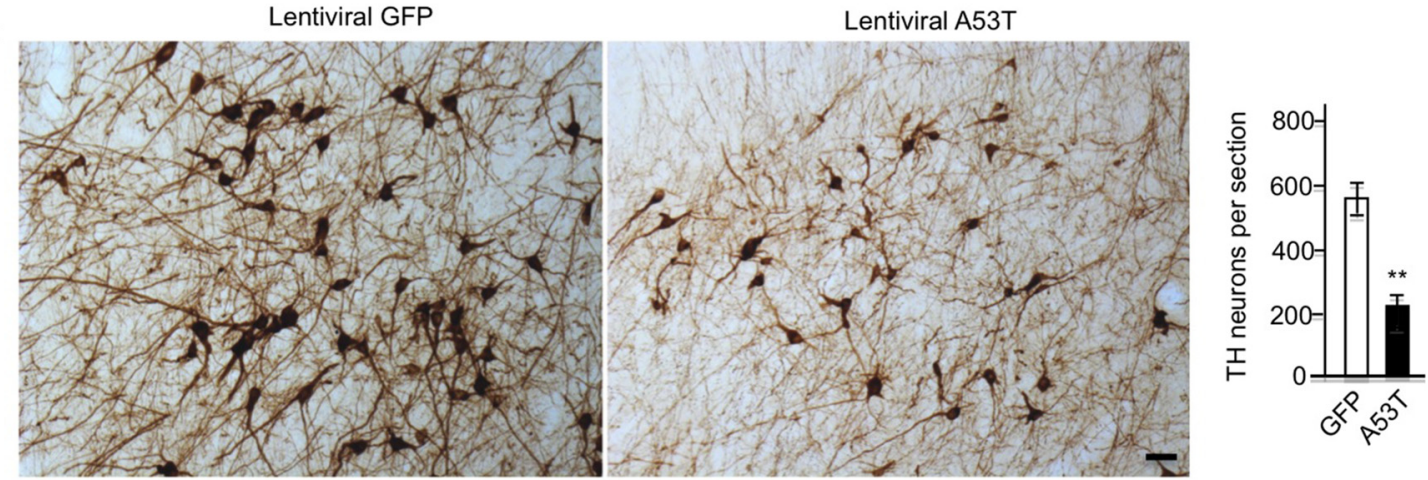

Figure 5. Degeneration of neuronal cells in A53T-injected monkey brains. $A$, EM examination showing the specific axonal degeneration (arrows) and reactive astrocytes (arrowheads) in lentiviral A53T- but not GFP-injected monkey brain. $\boldsymbol{B}$, High-magnification EM micrograph showing a degenerated axon (arrows) and reactive astrocytes (arrowheads) in A53T-injected monkey brain (top). Enlarged images also show dark and degenerated organelles in degenerated axons (bottom). C, Substantia nigra of a rhesus monkey at 8 years of age was immunostained with anti-TH after injection of lentiviral A53T or lentiviral GFP for 3 months. The density (the number of cells per section) of TH-positive neurons was reduced in the lentiviral A53T-injected region. Scale bars: $A, B, 2 \mu \mathrm{m} ; C, 10 \mu \mathrm{m}$. 
A
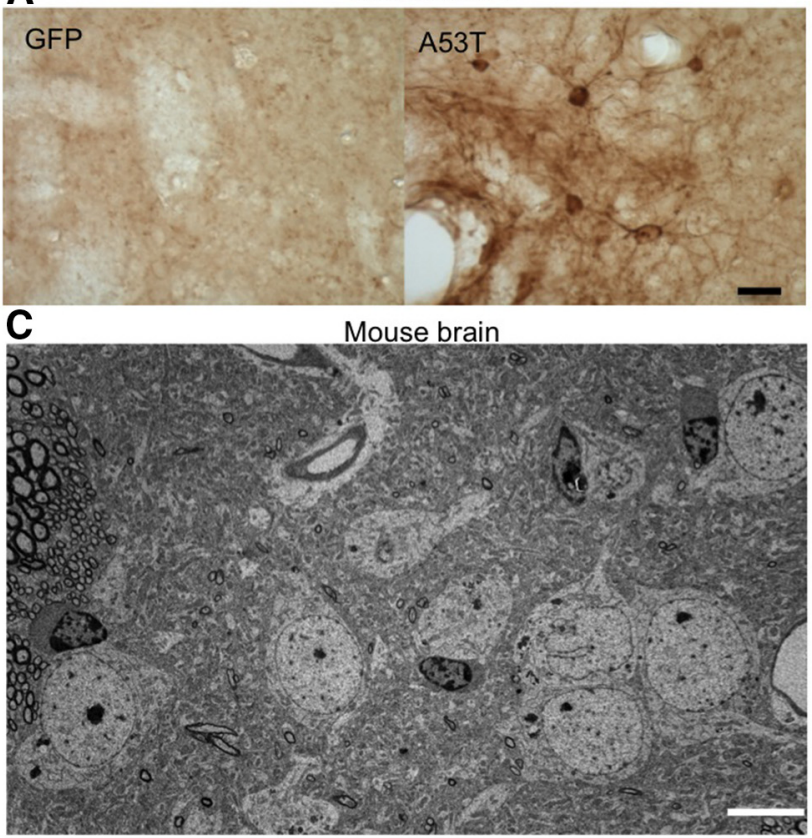

Monkey brain

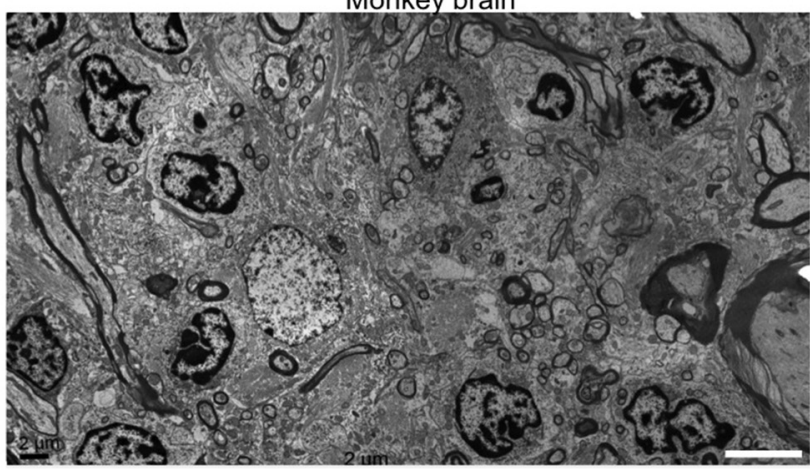

B Monkey brain
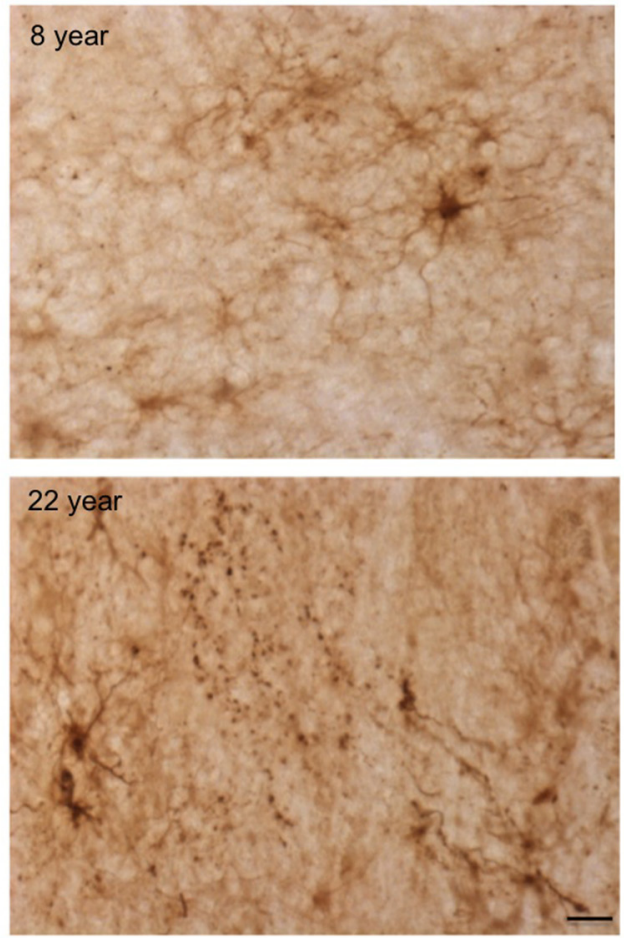

D

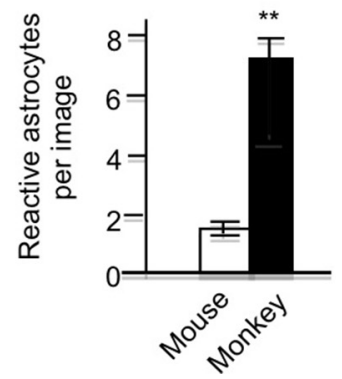

Figure 6. A53T causes more neurodegeneration in monkey brain than in mouse brain. A, Injection of lentiviral GFP or A53T-ECFP into the striatum of 10-month-old mice demonstrating specific staining of transgenic A53T by the antibody to anti- $\alpha$-syn. B, A53T-injected substantia nigra in monkeys at 8 and 22 years of age. Note that there are more fragmented neuronal processes or Lewy neurites labeled by anti- $\alpha$-syn in the older monkey brain. C, Comparison of the ultrastructure of the viral A53T-injected regions in 10-month-old mouse and 8-year-old monkey via EM showing more reactive astrocytes in the monkey brain. $\boldsymbol{D}$, Quantitation of reactive astrocytes per EM image $(4000 \times)$. The data are mean \pm SEM from randomly selected images $(5-10)$ per section $(n=5-8$ sections). ${ }^{*} p<0.05,{ }^{* *} p<0.01$. Scale bars: $A, B, 10 \mu \mathrm{m} ; \boldsymbol{C}, 5 \mu \mathrm{m}$.

pressed A53T precipitated more neurofascin than endogenous monkey $\alpha$-syn (Fig. 7D).

Because we wanted to know whether aging could promote the interaction of $\alpha$-syn with neurofascin and thus enhance the potential effect of $\alpha$-syn on neurofascin, we first examined the expression of neurofascin in the front cortex lysates from monkeys at different ages. Western blot analysis did not show any significant changes of neurofascin in monkey brain tissues at different ages (Fig. 8A). Because we found that aging promotes the accumulation of $\alpha$-syn in the monkey brain (Fig. 1), the increased levels of $\alpha$-syn would compromise the interpretation of immunoprecipitated neurofascin results when both endogenous proteins are immunoprecipitated. We thus used the same amount of GST-A53T to incubate with brain cortical tissue lysates from rhesus monkeys at different ages to evaluate how aged monkey tissues influence the interaction between GST-A53T and neurofascin (Fig. $8 B, C)$. We first verified the specific interaction of GST-A53T, but not GST, with brain neurofascin. Importantly, we saw that 8 -yearold monkey brain tissues did show an increased interaction be- tween GST-A53T and neurofascin (Fig. 8C). To better quantify their interactions when incubated with brain cortical tissues from monkeys at different ages, we examined three monkey brains at each age (2, 7-8, and $>15$ years) via GST-pulldown and Western blotting (Fig. $8 D$ ). The intensity of the pulled down neurofascin was quantified by measuring its ratios to the input and GSTA53T. Both quantifications show that aged monkey brain tissues also enhance the interaction of A53T with neurofascin (Fig. 8E).

\section{Protective effect of neurofascin on A53T neurotoxicity}

We recently generated transgenic A53T monkeys and obtained a stillborn monkey brain to analyze the expression of transgenic A53T (Niu et al., 2015). Although this stillborn monkey provided us with a limited number of brain slices containing the striatum, we wanted to see whether neurons expressing transgenic A53T show any defective morphology. Therefore, we performed immunodouble labeling with an antibody to MAP2 (the microtubule-associated protein 2) that is enriched in neuronal processes and found that some A53T-positive neurons (16 of the 
A

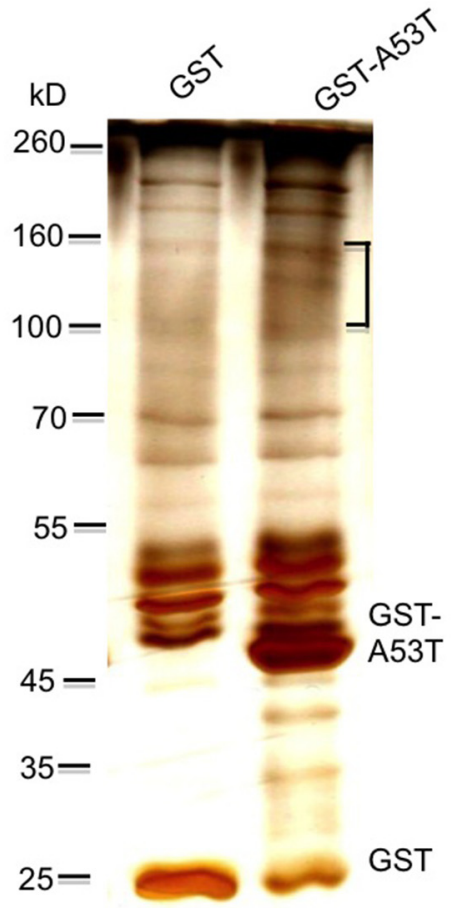

C

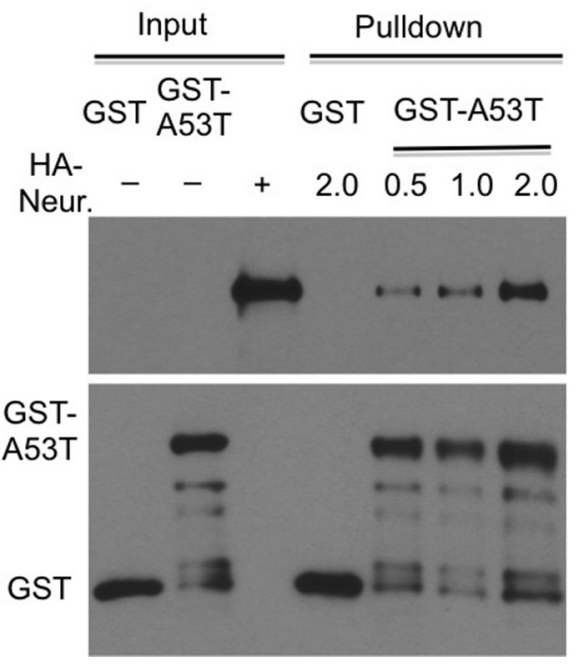

B

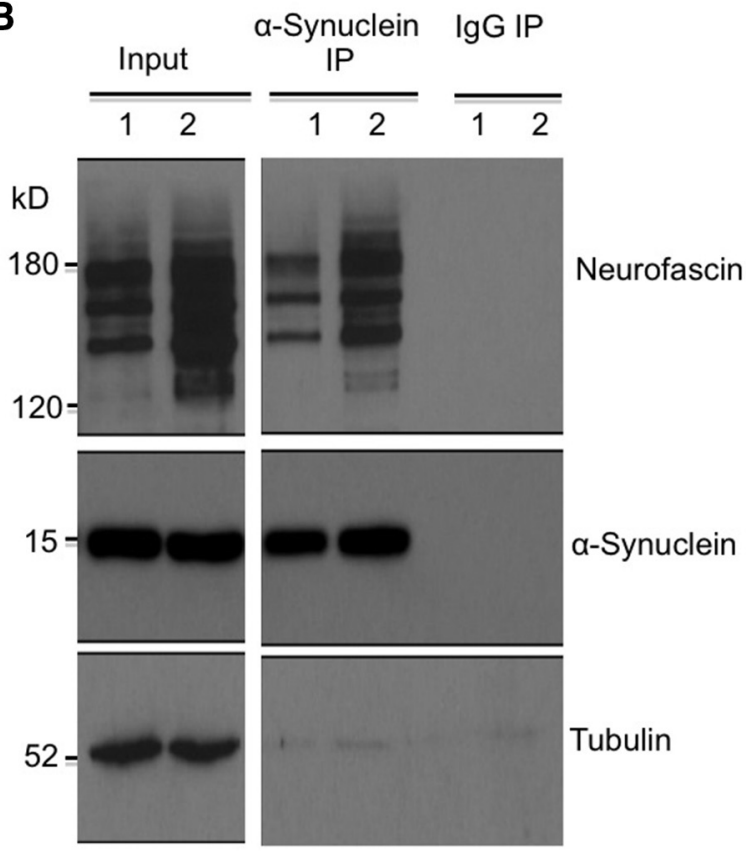

D

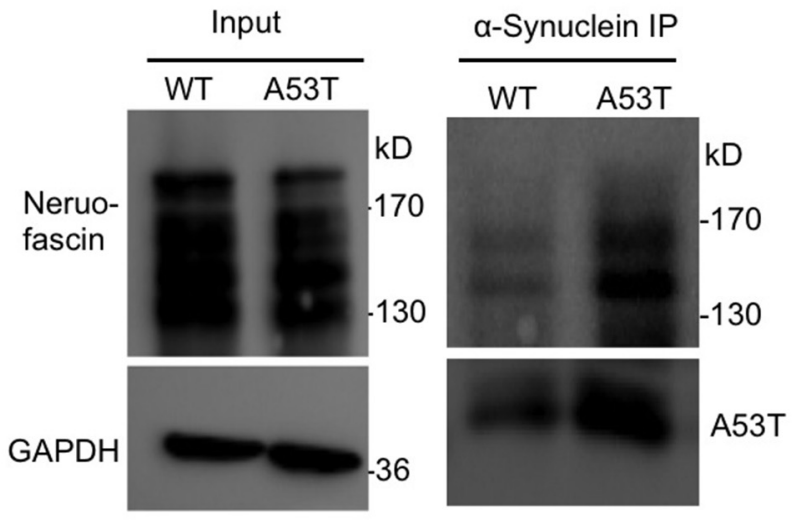

Figure 7. A53T binds neurofascin in monkey brain. A, GST pulldown of monkey brain substantia nigra tissues demonstrated that some proteins (bracket) were pulled down by GST-A53T. GST alone served as a control. These proteins were subjected to mass spectrometry and neurofascin was uncovered. $\boldsymbol{B}$, Immunoprecipitation of $\alpha$-syn from monkey brain cortex shows the coprecipitation of neurofascin (Neur) and $\alpha$-syn. Two immunoprecipitations are presented. C, Direct in vitro interaction of purified GST-A53T with purified recombinant neurofascin (HA-Neur) at increased doses $(0.5-2.0 \mu \mathrm{g})$. D, Immunoprecipitation of the substantia nigra of an 8-year-old rhesus monkey that was injected with lentiviral A53T, showing that overexpressed A53T binds more neurofascin.

total 182 cells examined) displayed obvious fragmented neuronal processes in the striatum and cortex (Fig. 9A), consistent with the neurite degeneration seen in viral A53T-injected brains. Therefore, the toxicity of A53T to neuronal processes appears to be an important early pathologic effect.

Overexpression of mutant $\alpha$-syn in neuronal cells results in cellular toxicity, which has been used to evaluate the protective effects of potential therapeutic chemicals or molecules (Stefanis et al., 2001; Lee and Trojanowski, 2006; Gupta et al., 2008; Kanthasamy et al., 2010). To test the functional relevance of the interaction between $\mathrm{A} 53 \mathrm{~T}$ and neurofascin, we used cultured PC12 cells as a model to test the neurite extension property because these cells differentiate to elongate their neurites in response to nerve growth factor (NGF). After inducing neurite outgrowth of PC12 cells with NGF (50 ng/ml), we found that expression of A53T suppressed neurite outgrowth, similar to an earlier report (Stefanis et al., 2001; Fig. $9 B)$. When PC12 cells were transfected with neurofascin, their neurite outgrowth was promoted (Fig. 9B). Importantly, the coexpression of neurofascin could partially rescue the neurite outgrowth impairment by transfected A53T compared with control cells that were transfected with A53T and vector (Fig. 9C). Because overexpressed A53T could mediate neurotoxicity by affecting multiple cellular functions, the partial rescue effect suggests that the interaction of overexpressed A53T with endogenous neurofascin likely affects neurite outgrowth and 
A
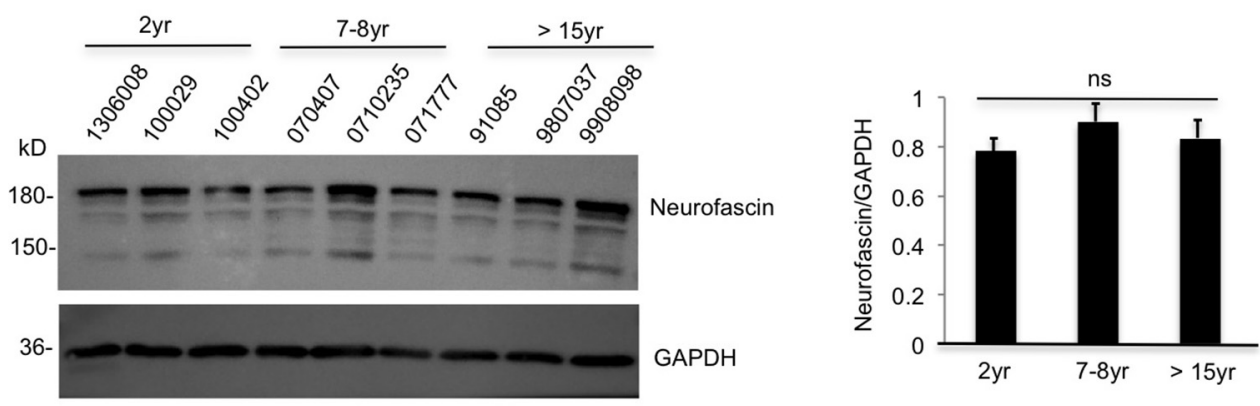

B
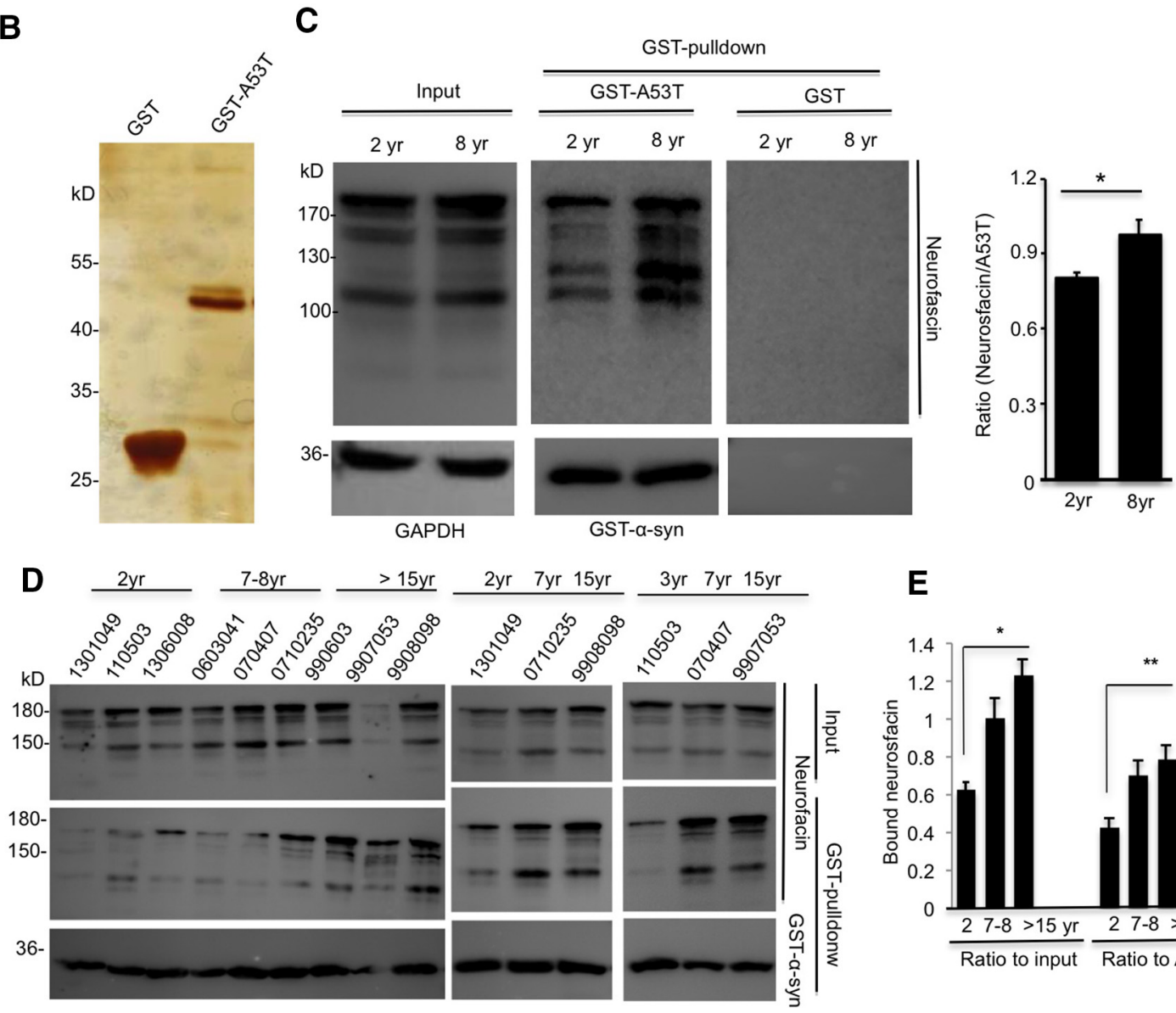

E

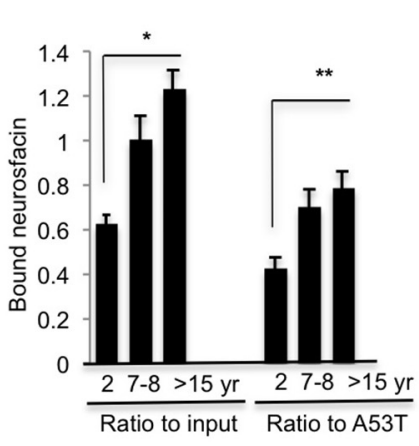

Figure 8. Aged monkey brain tissues show increased interaction of A53T with neurofascin. $\boldsymbol{A}$, Western blot analysis of the expression of neurofascin in monkey brain cortex at different ages. $\boldsymbol{B}$, Silver staining of SDS gel showing the purified GST and GST-A53T used for binding to tissue lysates from rhesus monkey cortex. C, GST-pulldown assay showing that only GST-A53T, not GST, binds neurofascin in monkey brain tissue lysates and that this binding is increased in 8-year-old compared with 2-year-old monkey brain. $D$, GST pulldown of brain cortex tissue lysates from multiple monkeys at different ages ( $n=3$ animals each age). Results show the increased binding of A53T to neurofascin in old monkey tissues. $E$, Ratios of pulled down neurofascin to the input or to GST-A53T used for binding. The data are shown as mean $\pm \mathrm{SE} .{ }^{*} p<0.05,{ }^{* *} p<0.01$.

that transfected neurofascin can reduce this effect by binding to overexpressed A53T.

\section{Discussion}

The aging processes in rodents and primates vary significantly, which may account for the differential pathology caused by mutant proteins in the brains of rodents and human patients. In PD, mutant $\alpha$-syn deposition can cause significant neuronal dysfunction in the absence of neuronal loss (Hall et al., 2014). In the current study, we provide evidence that aging is indeed a key to mutant $\alpha$-syn A53T deposition and toxicity in primate brains. In addition, by exploring the mechanism underlying the neuritic toxicity of mutant $\alpha$-syn, we found that neurofascin interacts with A53T and its overexpression can reduce A53T toxicity.

$\alpha$-syn is an abundant presynaptic phosphoprotein that may be involved in intracellular trafficking and many other cellular functions (Bendor et al., 2013). Its accumulation in aged brain is critical for neurotoxicity in PD pathology because duplication and triplication of the $\alpha$-syn gene are associated with PD (Singleton et al., 2003; Chartier-Harlin et al., 2004). Consistently, overexpression of wildtype $\alpha$-syn in animals also causes neuropathology and PD symptoms (Lo Bianco et al., 2002; Eslamboli et al., 2007; Sacino et al., 2014). It has been found that wild-type human $\alpha$-syn protects against manganese-induced dopaminergic neurotoxicity during the 
A
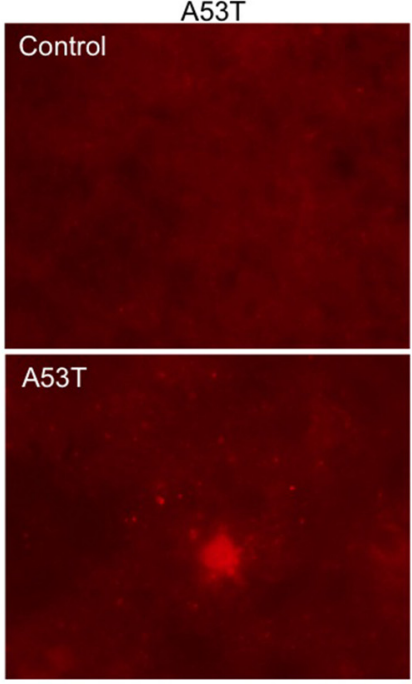

B

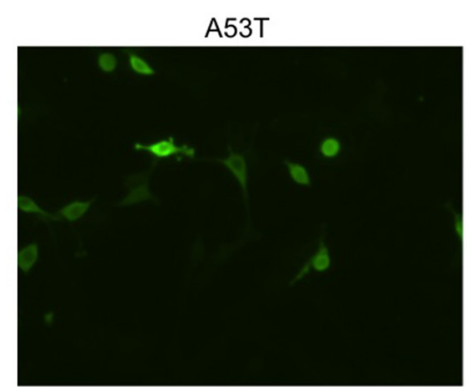

Double A53T and neurofascin transfection

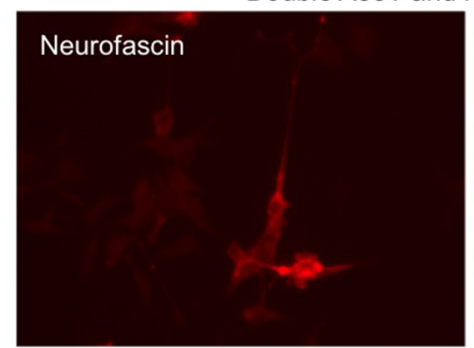

Map2
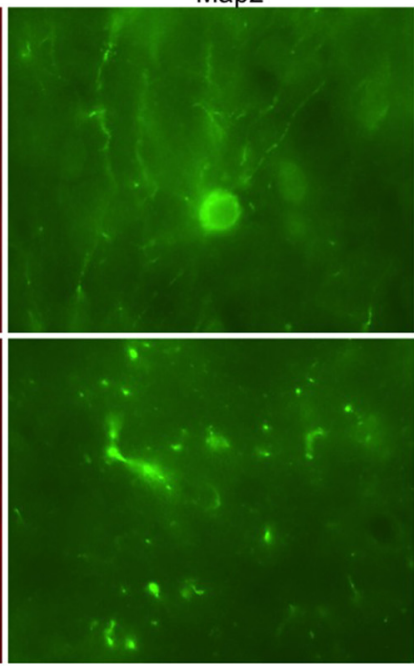

Neurofascin
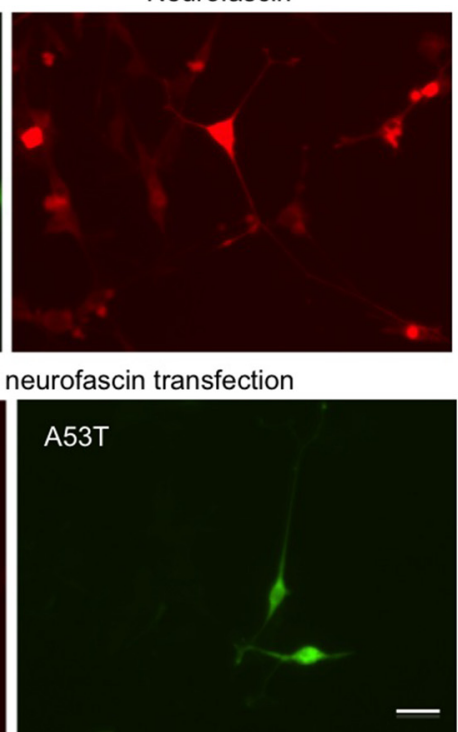

Merged
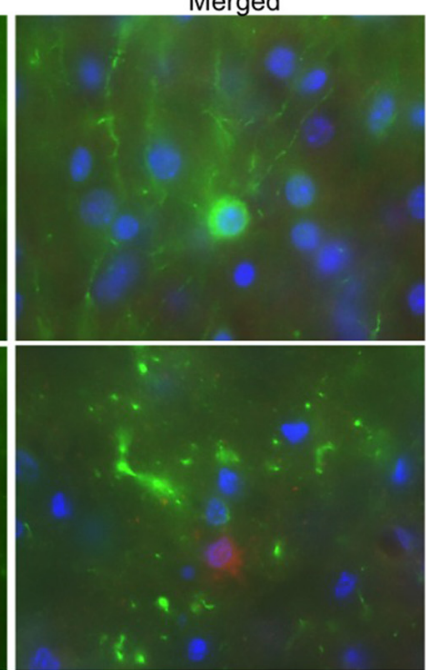

C

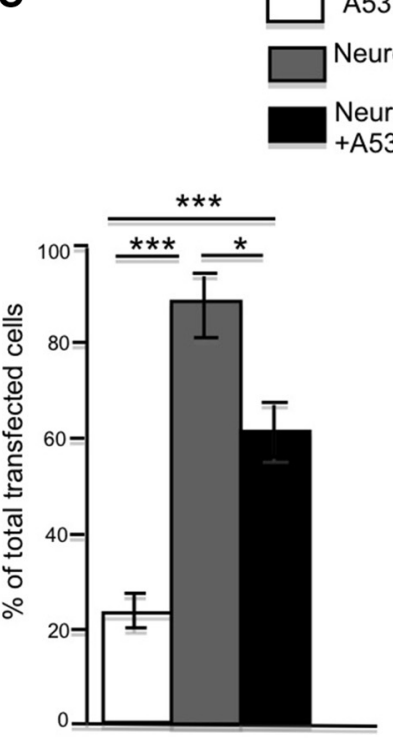

Figure 9. Protective effect of neurofascin on neuritic toxicity of A53T. A, Double immunofluorescent staining of transgenic A53T monkey brain striatum with an antibody to MAP2, a neuronal process protein, and anti- $\alpha$-syn, which reacts weakly with endogenous monkey $\alpha$-syn, but strongly with transgenic A53T. Note that some A53T-positive neurons show fragmented neuronal processes. $\boldsymbol{B}$, Transfection of neurofascin alleviates the defective neurite outgrowth of $\mathrm{PC} 12$ cells caused by transfected A53T. The cells were doubly immunofluorescence stained with antibodies to $\alpha$-syn and neurofascin. Note that A53T expression alone suppresses neurite outgrowth. C, Quantitative data showing the percentage of cells with elongated (longer than two cell body size) neurites ( $n \geq 60$ transfected cells per group). ${ }^{*} p<0.05,{ }^{* * *} p<0.001$. Scale bars, $10 \mu \mathrm{m}$.

early stages of neurotoxic stress, but the protein starts to aggregate at the later stages of neurotoxic stress, leading to neuronal death (Harischandra et al., 2015), also suggesting that the accumulation of $\alpha$-syn is important for neuronal cell death. Mutations in $\alpha$-syn may increase the propensity for its misfolding and accumulation that lead to its toxic effects in neuronal cells. Of the mutations identified in $\alpha$-syn, A53T has been characterized extensively for its toxicity and turnover in various cellular and animal models. The clearance of $\alpha$-syn is mediated by the ubiquitin-proteasome system (UPS) and autophagy (EbrahimiFakhari et al., 2011). We recently found that UPS activity declines in both monkey striatum and cortex in an age-dependent manner (Yin et al., 2015). Therefore, the age-related decrease in UPS activity likely accounts for the increased accumulation of $\alpha$-syn because the clearance of $\alpha$-syn is also mediated by the UPS (Xie et al., 2010; Abeywardana et al., 2013). Because the substantia nigra is smaller than the cortex and striatum, it is difficult to obtain enough fresh substantia nigra tissues for biochemical and Western blotting assays. Nevertheless, although we were unable to obtain enough substantia nigra tissues to examine their UPS activity and $\alpha$-syn expression, the histological examination of the substantia nigra allowed us to investigate how aging influences the level of mutant $\alpha$-syn (A53T) that was expressed for the same period of time in monkeys at different ages. This assay revealed an agedependent increase in the accumulation of A53T and associated pathology, such as increases in reactive gliosis and Lewy neurites.

Because the toxicity of mutant $\alpha$-syn is dependent on its expression level, it is important to compare the toxicity of mutant $\alpha$-syn in different species when they express the same transgene under the control of the same vector and promoter. Therefore, we 
compared the toxicity of lentiviral A53T in mouse and monkey brains and selected the injected regions that expressed A53T for the same period of time and showed a similar density of Lewy neurites or neuritic A53T deposition. This comparison suggests that A53T induces age-dependent toxicity and more severe neurotoxicity in monkey brains than in mouse brains, which is reflected by an increase in reactive astrocytes and axonal degeneration in monkey brain. Although this finding is consistent with the notion that A53T causes differential neuropathology in rodents and primates, the mechanisms for this difference remain to be investigated and merit discussion here. In our studies, we used stereotaxic injection to deliver the lentiviral A53T into the substantia nigra of mouse and monkey brains. The expression levels of lentiviral A53T are determined by which area is injected, viral vector doses, and expression times, as well as the transduction efficiency of lentiviral vectors in rodent and primate neuronal cells. Therefore, immunocytochemical analysis would be a better assay to reveal the expression of A53T in neuronal cells, especially in their neurites, in the injected region. Although rodent and monkey neurons show a similar distribution and abundance of A53T in their neurites, EM revealed a significant increase in reactive astrocytes in the injected monkey brain region. This finding suggests that primate neuronal cells are more sensitive to toxic $\alpha$-syn and therefore display greater neuronal damage than rodent neuronal cells. This finding is consistent with the fact that transgenic A53T mouse models do not have the significant neuronal loss in the substantia nigra as seen in PD patients (Beal, 2010; Dawson et al., 2010). It has been well documented that $\alpha$-syn in glial cells also plays an important role in PD pathology (Piao et al., 2003; Gu et al., 2010; Brück et al., 2015). Because transgenic A53T is expressed under the ubiquitin promoter in the lentiviral vector in our studies, the transgenic A53T is likely expressed in glial cells and the glial A53T may also contribute to the pathology seen in the viral A53T-injected monkey brains.

There are many possibilities to explain why rodent neuronal cells are more resistant to mutant $\alpha$-syn. One possibility is that the short life span of rodents does not allow the neurons at 10 months in the mouse brain to develop the same pathology as those neurons in monkey brains at 8 years of age. Another possibility is that the times for the development and maturation of the CNS in rodents and monkeys are significantly different $(21 \mathrm{~d}$ for mice vs $156 \mathrm{~d}$ for monkeys). The rapid development in mouse brains could render rodent neuronal cells resistant to toxic and misfolded proteins, whereas neurons in the primate brains require much longer times to develop and mature and are also more vulnerable to insults and toxic peptides. In support of this idea, transgenic monkeys show axonal degeneration not found in transgenic mice expressing the same transgenic gene for Huntington's disease (Wang et al., 2008).

Our findings also suggest that the neuritic toxicity of mutant $\alpha$-syn is likely to involve its interaction with neurofascin. Neurofascin is an adhesion protein that plays a role in maintaining axonal integrity (Sherman et al., 2005; Kriebel et al., 2012). Antibodies to neurofascin are known to induce axonal injury and exacerbate axonal damage (Mathey et al., 2007; Lindner et al., 2013). Mouse models that lack neurofascin also disrupted nodal and paranodal complexes (Sherman et al., 2005). All of these findings suggest that altered neurofascin levels can alter axonal integrity and lead to neuropathology. We found that $\alpha$-syn accumulates to a greater extent in monkey brains when monkeys age. Using brain tissue lysates from monkeys at different ages, we also saw an increased interaction between A53T and neurofascin. Although how aging promotes the interaction be- tween A53T and neurofascin remains to be investigated, the increased accumulation of mutant $\alpha$-syn and its interaction with neurofascin could affect the function of neurofascin and other molecules in neurites. This possibility is supported by the transfection of neurofascin in PC12 cells, which yielded protective effects to alleviate defective neurite outgrowth in PC12 cells, perhaps because its interaction with A53T prevents the effect of A53T on neurofascin and other molecules. Therefore, our studies not only demonstrate for the first time that aging promotes neurotoxicity of mutant $\alpha$-syn in primate brains, but also reveal a possible new therapeutic target for mutant $\alpha$-syn-mediated neuropathology.

\section{References}

Abeywardana T, Lin YH, Rott R, Engelender S, Pratt MR (2013) Sitespecific differences in proteasome-dependent degradation of monoubiquitinated alpha-synuclein. Chem Biol 20:1207-1213. CrossRef Medline

Beal MF (2010) Parkinson's disease: a model dilemma. Nature 466:S8-S10. CrossRef Medline

Becker G (2003) Methods for the early diagnosis of Parkinson's disease. Nervenarzt 74:S7-S11. CrossRef Medline

Bendor JT, Logan TP, Edwards RH (2013) The function of alpha-synuclein. Neuron 79:1044-1066. CrossRef Medline

Brás J, Guerreiro R, Hardy J (2015) SnapShot: genetics of Parkinson's disease. Cell 160:570-570.e1. CrossRef Medline

Brück D, Wenning GK, Stefanova N, Fellner L (2015) Glia and alphasynuclein in neurodegeneration: a complex interaction. Neurobiol Dis. In press.

Chartier-Harlin MC, Kachergus J, Roumier C, Mouroux V, Douay X, Lincoln S, Levecque C, Larvor L, Andrieux J, Hulihan M, Waucquier N, Defebvre L, Amouyel P, Farrer M, Destée A (2004) Alpha-synuclein locus duplication as a cause of familial Parkinson's disease. Lancet 364:1167-1169. CrossRef Medline

Chung CY, Khurana V, Auluck PK, Tardiff DF, Mazzulli JR, Soldner F, Baru V, Lou Y, Freyzon Y, Cho S, Mungenast AE, Muffat J, Mitalipova M, Pluth MD, Jui NT, Schüle B, Lippard SJ, Tsai LH, Krainc D, Buchwald SL, Jaenisch R, Lindquist S (2013) Identification and rescue of alphasynuclein toxicity in Parkinson patient-derived neurons. Science 342: 983-987. CrossRef Medline

Dawson TM, Ko HS, Dawson VL (2010) Genetic animal models of Parkinson's disease. Neuron 66:646-661. CrossRef Medline

Ebrahimi-Fakhari D, Cantuti-Castelvetri I, Fan Z, Rockenstein E, Masliah E, Hyman BT, McLean PJ, Unni VK (2011) Distinct roles in vivo for the ubiquitin-proteasome system and the autophagy-lysosomal pathway in the degradation of alpha-synuclein. J Neurosci 31:14508-14520. CrossRef Medline

Eslamboli A, Romero-Ramos M, Burger C, Bjorklund T, Muzyczka N, Mandel RJ, Baker H, Ridley RM, Kirik D (2007) Long-term consequences of human alpha-synuclein overexpression in the primate ventral midbrain. Brain 130:799-815. CrossRef Medline

Fearnley JM, Lees AJ (1991) Ageing and Parkinson's disease: substantia nigra regional selectivity. Brain 114:2283-2301. CrossRef Medline

Giasson BI, Duda JE, Quinn SM, Zhang B, Trojanowski JQ, Lee VM (2002) Neuronal alpha-synucleinopathy with severe movement disorder in mice expressing A53T human alpha-synuclein. Neuron 34:521-533. CrossRef Medline

Goedert M (2001) Alpha-synuclein and neurodegenerative diseases. Nat Rev Neurosci 2:492-501. CrossRef Medline

Gu XL, Long CX, Sun L, Xie C, Lin X, Cai H (2010) Astrocytic expression of Parkinson's disease-related A53T alpha-synuclein causes neurodegeneration in mice. Mol Brain 3:12. CrossRef Medline

Gupta A, Dawson VL, Dawson TM (2008) What causes cell death in Parkinson's disease? Ann Neurol 64:S3-S15. Medline

Hall H, Reyes S, Landeck N, Bye C, Leanza G, Double K, Thompson L, Halliday G, Kirik D (2014) Hippocampal Lewy pathology and cholinergic dysfunction are associated with dementia in Parkinson's disease. Brain 137:2493-2508. CrossRef Medline

Harischandra DS, Jin H, Anantharam V, Kanthasamy A, Kanthasamy AG (2015) $\alpha$-Synuclein protects against manganese neurotoxic insult during the early stages of exposure in a dopaminergic cell model of Parkinson's disease. Toxicol Sci 143:454-468. CrossRef Medline 
Hassel B, Rathjen FG, Volkmer H (1997) Organization of the neurofascin gene and analysis of developmentally regulated alternative splicing. J Biol Chem 272:28742-28749. CrossRef Medline

Kanthasamy A, Jin H, Mehrotra S, Mishra R, Kanthasamy A, Rana A (2010) Novel cell death signaling pathways in neurotoxicity models of dopaminergic degeneration: relevance to oxidative stress and neuroinflammation in Parkinson's disease. Neurotoxicology 31:555-561. CrossRef Medline

Kriebel M, Wuchter J, Trinks S, Volkmer H (2012) Neurofascin: A switch between neuronal plasticity and stability. Int J Biochem Cell Biol 44:694697. CrossRef Medline

Lee VM, Trojanowski JQ (2006) Mechanisms of Parkinson's disease linked to pathological alpha-synuclein: new targets for drug discovery. Neuron 52:33-38. CrossRef Medline

Lin X, Parisiadou L, Gu XL, Wang L, Shim H, Sun L, Xie C, Long CX, Yang WJ, Ding J, Chen ZZ, Gallant PE, Tao-Cheng JH, Rudow G, Troncoso JC, Liu Z, Li Z, Cai H (2009) Leucine-rich repeat kinase 2 regulates the progression of neuropathology induced by Parkinson's-disease-related mutant alpha-synuclein. Neuron 64:807-827. CrossRef Medline

Lindner M, Ng JK, Hochmeister S, Meinl E, Linington C (2013) Neurofascin 186 specific autoantibodies induce axonal injury and exacerbate disease severity in experimental autoimmune encephalomyelitis. Exp Neurol 247:259-266. CrossRef Medline

Lo Bianco C, Ridet JL, Schneider BL, Deglon N, Aebischer P (2002) alphaSynucleinopathy and selective dopaminergic neuron loss in a rat lentiviral-based model of Parkinson's disease. Proc Natl Acad Sci U S A 99:10813-10818. CrossRef Medline

Magen I, Chesselet MF (2011) Mouse models of cognitive deficits due to alpha-synuclein pathology. J Parkinsons Dis 1:217-227. Medline

Mathey EK, Derfuss T, Storch MK, Williams KR, Hales K, Woolley DR, Al-Hayani A, Davies SN, Rasband MN, Olsson T, Moldenhauer A, Velhin S, Hohlfeld R, Meinl E, Linington C (2007) Neurofascin as a novel target for autoantibody-mediated axonal injury. J Exp Med 204:2363-2372. CrossRef Medline

Neumann M, Kahle PJ, Giasson BI, Ozmen L, Borroni E, Spooren W, Muller V, Odoy S, Fujiwara H, Hasegawa M, Iwatsubo T, Trojanowski JQ, Kretzschmar HA, Haass C (2002) Misfolded proteinase K-resistant hyperphosphorylated alpha-synuclein in aged transgenic mice with locomotor deterioration and in human alpha-synucleinopathies. J Clin Invest 110: 1429-1439. Medline

Niu Y, Guo X, Chen Y, Wang CE, Gao J, Yang W, Kang Y, Si W, Wang H, Yang SH, et al. (2015) Early Parkinson's disease symptoms in alpha-synuclein transgenic monkeys. 24:2308-2317.

Olanow CW, Tatton WG (1999) Etiology and pathogenesis of Parkinson's disease. Annu Rev Neurosci 22:123-144. CrossRef Medline

Piao YS, Mori F, Hayashi S, Tanji K, Yoshimoto M, Kakita A, Wakabayashi K, Takahashi H (2003) Alpha-synuclein pathology affecting Bergmann glia of the cerebellum in patients with alpha-synucleinopathies. Acta Neuropathol 105:403-409. Medline

Ponsen MM, Stoffers D, Booij J, van Eck-Smit BL, Wolters ECh, Berendse
HW (2004) Idiopathic hyposmia as a preclinical sign of Parkinson's disease. Ann Neurol 56:173-181. CrossRef Medline

Sacino AN, Brooks M, McKinney AB, Thomas MA, Shaw G, Golde TE, Giasson BI (2014) Brain injection of alpha-synuclein induces multiple proteinopathies, gliosis, and a neuronal injury marker. J Neurosci 34:12368-12378. CrossRef Medline

Sherman DL, Tait S, Melrose S, Johnson R, Zonta B, Court FA, Macklin WB, Meek S, Smith AJ, Cottrell DF, Brophy PJ (2005) Neurofascins are required to establish axonal domains for saltatory conduction. Neuron 48 : 737-742. CrossRef Medline

Singleton AB, Farrer M, Johnson J, Singleton A, Hague S, Kachergus J, Hulihan M, Peuralinna T, Dutra A, Nussbaum R, Lincoln S, Crawley A, Hanson M, Maraganore D, Adler C, Cookson MR, Muenter M, aptista M, Miller D, Blancato J, Hardy J, Gwinn-Hardy K (2003) Alpha-synuclein locus triplication causes Parkinson's disease. Science 302:841. CrossRef Medline

Spillantini MG, Crowther RA, Jakes R, Hasegawa M, Goedert M (1998) alpha-Synuclein in filamentous inclusions of Lewy bodies from Parkinson's disease and dementia with lewy bodies. Proc Natl Acad Sci U S A 95:6469-6473. CrossRef Medline

Stefanis L, Larsen KE, Rideout HJ, Sulzer D, Greene LA (2001) Expression of A53T mutant but not wild-type alpha-synuclein in PC12 cells induces alterations of the ubiquitin-dependent degradation system, loss of dopamine release, and autophagic cell death. J Neurosci 21:9549-9560. Medline

Stiasny-Kolster K, Doerr Y, Möller JC, Höffken H, Behr TM, Oertel WH, Mayer G (2005) Combination of 'idiopathic' REM sleep behaviour disorder and olfactory dysfunction as possible indicator for alpha-synucleinopathy demonstrated by dopamine transporter FP-CIT-SPECT. Brain 128:126-137. Medline

Vierck JL, Bryne KM, Dodson MV (2000) Evaluating dot and Western blots using image analysis and pixel quantification of electronic images. Methods Cell Sci 22:313-318. CrossRef Medline

Wang CE, Tydlacka S, Orr AL, Yang SH, Graham RK, Hayden MR, Li S, Chan AW, Li XJ (2008) Accumulation of N-terminal mutant huntingtin in mouse and monkey models implicated as a pathogenic mechanism in Huntington's disease. Hum Mol Genet 17:2738-2751. CrossRef Medline

Xie W, Li X, Li C, Zhu W, Jankovic J, Le W (2010) Proteasome inhibition modeling nigral neuron degeneration in Parkinson's disease. J Neurochem 115:188-199. CrossRef Medline

Yin P, Tu Z, Yin A, Zhao T, Yan S, Guo X, Chang R, Zhang L, Hong Y, Huang X, Zhou J, Wang Y, Li S, Li XJ (2015) Aged monkey brains reveal the role of ubiquitin-conjugating enzyme UBE2N in the synaptosomal accumulation of mutant huntingtin. Hum Mol Genet 24:1350-1362. CrossRef Medline

Zhang X, Davis JQ, Carpenter S, Bennett V (1998) Structural requirements for association of neurofascin with ankyrin. J Biol Chem 273:3078530794. CrossRef Medline 